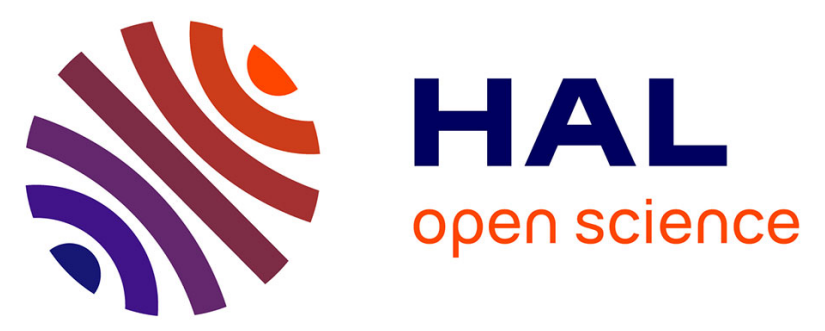

\title{
Identification of a novel type of glucose dehydrogenase involved in the mineral weathering ability of Collimonas pratensis strain PMB3(1)
}

Laura Picard, Marie-Pierre M.-P. Turpault, P. Oger, Stephane Uroz

\section{- To cite this version:}

Laura Picard, Marie-Pierre M.-P. Turpault, P. Oger, Stephane Uroz. Identification of a novel type of glucose dehydrogenase involved in the mineral weathering ability of Collimonas pratensis strain PMB3(1). FEMS Microbiology Ecology, 2020, 10.1093/femsec/fiaa232 . hal-03000681

\section{HAL Id: hal-03000681 https://hal.science/hal-03000681}

Submitted on 5 Jan 2021

HAL is a multi-disciplinary open access archive for the deposit and dissemination of scientific research documents, whether they are published or not. The documents may come from teaching and research institutions in France or abroad, or from public or private research centers.
L'archive ouverte pluridisciplinaire HAL, est destinée au dépôt et à la diffusion de documents scientifiques de niveau recherche, publiés ou non, émanant des établissements d'enseignement et de recherche français ou étrangers, des laboratoires publics ou privés. 
Picard et al.

1 TITLE: Identification of a novel type of glucose dehydrogenase involved in the mineral

2 weathering ability of Collimonas pratensis strain PMB3(1)

4 Running title: Mineral weathering by a glucose dehydrogenase

5

6 AUTHORS: Picard, L. ${ }^{1,2}$, Turpault, M-P. ${ }^{2}$, Oger, P.M. ${ }^{3}$, Uroz, S. ${ }^{1,2 \#}$

7

$8{ }^{1}$ Université de Lorraine, INRAE, UMR1136 « Interactions Arbres-Microorganismes », F954280 Champenoux, France

102 INRAE, UR1138 « Biogéochimie des écosystèmes forestiers », F-54280 Champenoux, 11 France

$12 \quad{ }^{3}$ Université de Lyon, INSA de Lyon, CNRS UMR 5240, Lyon, France

\# Corresponding author: Mailing address:

Université de Lorraine, INRAE, “Interactions Arbres Microorganismes”, UMR 1136, 54280 Champenoux, France. Phone: +33 (0)3 833940 81, Fax: +33 (0)3 833940 69. E-mail: stephane.uroz@inra.fr.

Key words: Collimonas pratensis PMB3(1), mineral weathering, Glucose/Methanol/Choline oxidoreductase, PQQ-independent glucose dehydrogenase, biotite 
Picard et al.

\section{ABSTRACT}

The exact molecular mechanisms as well as the genes involved in the mineral weathering (MW) process by bacteria remain poorly characterized. To date, a single type of glucose dehydrogenase (GDH) depending on a particular co-factor named pyrroloquinoline quinone (PQQ) is known. These enzymes allow the production of gluconic acid through the oxidation of glucose. However, it remains to be determined how bacteria missing PQQ-dependent GDH and/or the related $p q q$ biogenesis genes weather minerals. In this study, we considered the very effective mineral weathering bacterial strain PMB3(1) of Collimonas pratensis. Genome analysis revealed that it does not possess the PQQ based system. The use of random mutagenesis, gene complementation and functional assays allowed us to identify mutants impacted in their ability to weather mineral. Among them, three mutants were strongly altered on their acidification and biotite weathering abilities (58 to $75 \%$ of reduction compared to WT) and did not produce gluconic acid. The characterization of the genomic regions allowed noticeably to the identification of a Glucose/Methanol/Choline oxidoreductase. This region appeared very conserved among collimonads and related genera. This study represents the first demonstration of the implication of a PQQ-independent GDH in the mineral weathering process and explains how Collimonas weather minerals. 
Picard et al.

\section{INTRODUCTION}

Minerals represent physical supports and reservoirs of nutritive elements for the development of the biosphere. Their dissolution, i.e., mineral weathering (MW), participates in the release of their nutritive constituents. This essential process permits to maintain the relative fertility of the soils and to support the growth of the plants. In nutrient-poor and nonamended environments such as forests, minerals are considered as one of the most important stock of nutrients for the long-lasting development of the ecosystem (Ranger and Turpault, 1999). However, MW is a slow process, which depends on the intrinsic properties of those minerals (i.e., dissolution constant) and extrinsic conditions that result from a combination of abiotic and biotic processes. For instance, in acidic draining medium, biotite dissolves faster than quartz because of their intrinsic properties (i.e., chemical composition) (Brantley, 2008). In drained soils, water and acid circulation are known as important abiotic factors involved in the dissolution of minerals. Plants and soil microorganisms are also known to participate in this process (Gadd, 2007; Landeweert et al. 2001). Tree roots and fungal hyphae can physically weather minerals (i.e., division) through the pressure applied (Bonneville et al. 2009). Plant development through nutrient pumping and rhizosphere acidification induces stronger MW than in the surrounding bulk soil (Calvaruso et al. 2009; Turpault et al. 2009; Hinsinger et al. 2003). The production of chelating and acidifying agents was also reported for a wide range of plants, symbiotic fungi and bacteria (Jongmans et al. 1997; Uroz et al. 2009a).

Effective MW bacteria have been described in various environments, and especially in the rhizosphere of different plants (i.e., trees, cactus) living in nutrient-poor environments (Puente et al. 2004). Notably, several studies evidenced a significant enrichment of these functional communities in the rhizosphere compared to the surrounding bulk soil (Collignon et al. 2011; Calvaruso et al. 2010; Zhang et al. 2016). In addition, microcosm experiments revealed that 
Picard et al.

effective MW bacterial strains can improve plant growth. Indeed, the inoculation or coinoculation of different MW bacterial strains was shown to increase the seedling biomass, the shoot length, the root biomass, the total root length and the total root surface area of Pinus sylvestris compared to non-inoculated plants (Calvaruso et al. 2006; Koele et al. 2009). To date, the ability to solubilize mineral has been reported for a wide range of bacterial genera (i.e., Achromobacter, Agrobacterium, Bacillus, Collimonas, Pseudomonas, Rhizobium, Burkholderia, Microccocus, Aereobacter, Flavobacterium or Erwinia) (Puente et al. 2004; , Collignon et al. 2011; Rodriguez and Fraga, 1999; Uroz et al. 2011).

If the ability of the bacteria to weather minerals is well documented, our understanding of the molecular basis and especially of the genes involved in MW remains limited. This gap of knowledge has seriously hampered studies of the ecology, evolution and relative role of the mineral weathering bacteria. To date, no molecular tools exist to assess and quantify the occurrence, diversity, and activity of mineral weathering genes in natural bacterial populations. Heterotrophic bacteria are known to produce chelating agents (i.e., siderophores and organic acids) and acidifying metabolites (i.e., protons, organic acids), but the molecular demonstrations of their relative role in the MW process are limited as well as is our knowledge of the conservation among bacteria of the molecular markers involved. Considering the organic acid production, several studies showed that the direct oxidation pathway of glucose is involved and more specifically the steps producing gluconic acid (GA) and 2-ketogluconic acid (2KGA) through the activity of a glucose dehydrogenase (GDH) and a gluconate dehydrogenase (GADH), respectively (Goldstein, 1995). To date, the demonstration of the link between phosphate dissolution and the activity of the GDH activity was obtained on a wide range of bacterial genera. All these studies highlighted the implication of a specific type of GDH that depends on a particular cofactor, the pyrroloquinoline quinone (PQQ) (Goldstein et al. 2003; Babu-Khan et al. 1995; Liu et al. 1992; Wagh et al. 2014). 
Picard et al.

The implication of a PQQ-dependent GDH enzyme in the dissolution of a complex mineral, biotite, was recently evidenced for a strain of Pseudomonas (Wang et al. 2020).

In this study, we investigated the molecular basis of MW in the model bacterial strain Collimonas pratensis PMB3(1), which was shown to be very effective at MW (Uroz et al. 2007; Uroz et al. 2009a). This bacterial genus is usually considered as member of the rare biosphere due to its low representativeness in metagenomic data from soil (Levea $u$ et al. 2010). However, collimonads can represent dominant taxa in specific habitats such as on mineral particles or in the mycorrhizosphere (Lepleux et al. 2012; Uroz et al. 2012, Colin et al. 2017). Collimonads are recognized as particularly effective at mobilizing nutrients from recalcitrant sources such as chitin and minerals, suggesting that they are particularly well adapted to live in nutrient-poor conditions (Levea $u$ et al. 2010). Their strong MW effectiveness was suggested to be linked to their ability to acidify the medium in presence of glucose and to produce high amounts of gluconic acid (Uroz et al. 2009b). Using a random mutagenesis approach, associated to a functional screening and a gene complementation and chemical analyses, we identified the genes involved in the MW ability of strain PMB3(1) and evidenced a novel MW pathway involving a PQQ-independent, synthesis of gluconic acid, encoded by a glucose dehydrogenase (GDH).

\section{MATERIALS AND METHODS}

Bacterial strains and growth media. Bacterial strains and plasmids are listed in Table 1. The model bacterial strain Collimonas pratensis PMB3(1) considered in this study was isolated from oak (Quercus petraea)-Scleroderma citrinum ectomycorrhizae sampled in the organomineral soil horizon from the long term experimental forest site of Breuil-Chenue located in the Morvan region (France; for sampling details see Calvaruso et al. 2007). Strain PMB3(1) 
Picard et al.

was isolated from the symbiotic fungal mantle of the mycorrhizal fungus. Previous experiments showed that the strain PMB3(1) was particularly effective at weathering mineral (Uroz et al. 2007, 2009b). All strains were grown at $25^{\circ} \mathrm{C}$, except the strains of Escherichia coli, which were grown at $37^{\circ} \mathrm{C}$. The media used were Luria-Bertani (LB), AB medium (Chilton et al. 1974) and a modified version of the Bushnell-Haas (BHm; devoid of iron) medium (Uroz et a1. 2007). The $\mathrm{AB}$ minimal (ABm) medium was supplemented with mannitol (2 $\mathrm{g} / \mathrm{l}$ final concentration) as carbon source. The BHm medium was supplemented with glucose (2 g/l final concentration) as carbon source. Glucose was selected in our experiments because it represents the dominant carbohydrate source found in forest soil and in plant root exudates (Jolivet et al. 2006; Medeiros et al. 2006; Grayston and Campbell, 1996). Its presence is also explained by hydrolysis of various compounds such as starch, saccharose (Derrien et al. 2004) or by hydrolysis of trehalose, a carbohydrate accumulated in mycorrhizal roots (Martin et al. 1985). Antibiotics, when required, were added to the media at the following final concentrations: Tetracycline $10 \mu \mathrm{g} / \mathrm{ml}$, Kanamycin $100 \mu \mathrm{g} / \mathrm{ml}$ and Ampicillin $100 \mu \mathrm{g} / \mathrm{ml}$.

Tn5-OT182 mutagenesis. The wild-type strain PMB3(1) of $C$. pratensis was mutagenized with Tn5-OT182 as described previously (Deshazer et al. 1997; Dennis et al. 1998), with minor modifications. The donor strain, E. coli $\mathrm{S} 17-1 \lambda$ pir (pOT182), was grown at $37^{\circ} \mathrm{C}$ in antibiotic-containing LB broth overnight, and the recipient strain, C. pratensis PMB3(1), was grown at $25^{\circ} \mathrm{C}$ in $\mathrm{ABm}$ liquid medium for 2 days. The day of the bi-parental conjugation, each culture $(30 \mathrm{ml})$ was centrifuged and washed twice with sterile MQ water to remove any antibiotic from the medium and mixed in a final volume of $5 \mathrm{ml}$ of sterile MQ water. The mixed suspension was spotted on agar LB plates (i.e., $10 \mu 1$ drops). After $5 \mathrm{~h}$ of incubation at $25^{\circ} \mathrm{C}$, the bacterial lawn of each plate was harvested using sterile MQ water $(5 \mathrm{ml})$, and 150 
Picard et al.

$\mu \mathrm{l}$ of this suspension were plated on tetracycline-containing $\mathrm{ABm}$ plates for isolation of the Tn5 mutants of the strain PMB3(1). A total of 2,000 mutants able to grow on ABm supplemented with mannitol and tetracycline were recovered after 5 days incubation at $25^{\circ} \mathrm{C}$ and organized in 96-well microplates. To confirm the presence of the plasposon in the mutant genome, a portion of the plasposon sequence was amplified by PCR using pOT-For and pOTRev primers (Table 1). The quality of the mutant library was tested on a subset of Tn5 mutants and on the mutants of interest to determine whether the library was formed by independent events.

DNA manipulations and plasposon rescue. Total DNA was extracted from the WT strain PMB3(1) and the related Tn5 mutants using the protocol of Pospiech and Neumann (1995). The flanking Tn5-OT182 integration regions were identified using the rescue method as described previously (Deshazer et al. 1997). Briefly, $5 \mu \mathrm{g}$ of DNA of each mutant was digested $4 \mathrm{~h}$ with EcoRI-HF in $50 \mu \mathrm{l}$. After heat inactivation, the digested DNA was ligated overnight in $25 \mu \mathrm{l}$. A volume of $10 \mu \mathrm{l}$ was transformed into chemically competent $E$. coli DH5 $\alpha$ and the transformants recovered on the appropriate selective medium. The resulting plasmids were extracted using the Miniprep kit from QIAGEN and sequenced with the primer pOT-RT at Eurofins MWG Operon (https://www.eurofinsgenomics.eu/). All enzymes for restriction digestion and ligation were purchased from New England Biolabs and were used according to the manufacturers' instructions. When required, PCR amplicons were purified using QIAquick PCR purification and gel extraction kits from QIAGEN. PCR was performed using Taq polymerase from 5PRIME.

Construction of pB2-gdhC, pB2-resB and pB2-tatABC. The ineffective MW phenotype of three Tn5-OT182 mutants of the strain PMB3(1) were complemented by expressing each 
Picard et al.

gene or region of interest ( $g d h C$, resB and tat $A B C)$ in trans on plasmids $\mathrm{pB} 2$ - $g d h C, \mathrm{pB} 2$-res $B$ and $\mathrm{pB} 2$-tat $A B C$. These genes/regions were amplified using specific primers (Table 1). The conditions for PCR involved a 5 min denaturation step at $94^{\circ} \mathrm{C}$, followed by 30 cycles of $94^{\circ} \mathrm{C}$ for $45 \mathrm{~s}$, melting temperature $(\mathrm{Tm})$ for $45 \mathrm{~s}$, and $72^{\circ} \mathrm{C}$ for $2 \mathrm{~min} 30 \mathrm{~s}$. The $\mathrm{Tm}$ temperature was adapted according to the gene or region of interest. Each PCR product was purified and ligated into the pGEM-T Easy plasmid (Promega), and validated by Sanger sequencing (52). The gene $g d h C$ was cloned as a $K p n \mathrm{I}$ - SpeI fragment, the gene resB as a SacI - SpeI fragment, and the $t a t A B C$ genes as a SmaI - XbaI fragment into pBBR1MCS-2 (Kovach et al. $1995)$ to yield plasmids $\mathrm{pB} 2-\mathrm{gdhC}, \mathrm{pB} 2-\mathrm{res} B$ and $\mathrm{pB} 2-\operatorname{tat} A B C$ respectively. After verification by sequencing, the resulting constructs were transferred in chemically competent $E$. coli $\mathrm{S} 17$ $1 \lambda$ pir and conjugated to the corresponding Tn5-OT182 mutant. The complemented mutants were selected on agar $\mathrm{ABm}$ medium supplemented with tetracycline and kanamycin. The presence of the intact gene in the complemented mutants was verified by a PCR using the appropriate primers (Table 1), the WT strain was the positive control and the mutant was the negative control. For each construction, a single transconjugant was conserved after validation and used in the different bioassays described below.

Analysis and quantification of organic acids. After a 4-day culture $\left(25^{\circ} \mathrm{C} ; 200 \mathrm{rpm}\right)$ in liquid BHm amended with glucose $(2 \mathrm{~g} / \mathrm{l})$ and devoid of iron, the supernatants of cultures of the WT and Tn5-OT182 mutants were recovered by centrifugation (10,000g during $15 \mathrm{~min})$. The supernatants were then filtered at $0.22 \mu \mathrm{m}$ (GHP Acrodisc $25 \mathrm{~mm}$ syringe filter; PALL) and stored at $-20^{\circ} \mathrm{C}$. Organic acid analyses were performed on an ion chromatography with conductivity detection (ICS 3000, Dionex Corp.) associated to an analytical column (IonPac ${ }^{\circledR}$ AS $11 \mathrm{HC}$, Dionex corp.) according to Balland et al. (2010). The supernatants were eluted with $\mathrm{KOH}$ solutions of varying concentrations $(0.9-60 \mathrm{mM})$ over time (step gradient) with a 
Picard et al.

flow rate of $1.3 \mathrm{ml} / \mathrm{min}$. Synthetic organic acids have used as references (sodium formate, Dgluconic acid, sodium butyrate, pyruvic acid sodium salt, sodium citrate tribasic, sodium oxalate, sodium propionate, sodium acetate, succinic acid disodium salt, DL-malic acid disodium salt, sodium-L-lactate and malonic acid disodium salt).

Analysis of the production of gluconate, 2KGA and 5KGA. Qualitative analysis was performed using thin layer chromatography (TLC) to identify which form of gluconic acid was produced by the WT strain PMB3(1). To do it, cultures were done in ABm medium supplemented with $10 \mathrm{~g} / \mathrm{l}$ of glucose at $25^{\circ} \mathrm{C}$ and under shaking. After 4 days, the supernatant of culture was recovered and filtered at $0.22 \mu \mathrm{m}$ (GHP Acrodisc $25 \mathrm{~mm}$ syringe filter; PALL). A volume of $4 \mu 1$ for the standards and twice $4 \mu 1$ for the culture supernatants were spotted on a Silica Gel 60 plate (Merck). After drying at room temperature, migration was performed in a solvent reagent containing ethyl acetate-acetic acid-methanol and deionized water (6:1.5:1.5:1). When the TLC plate was dried, spread with a freshly prepared revelation solution (diphenylamine $(1 \mathrm{~g})$; aniline $(1 \mathrm{ml})$; acetone $(50 \mathrm{ml})$; phosphoric acid $(7.5 \mathrm{ml}))$. The treated TLC plate was then incubated at $120^{\circ} \mathrm{C}$ for $20 \mathrm{~min}$ to allow apparition of coloured spots. The results were analysed by measuring the retention factor (Rf) (corresponding to the distance moved by the sample divided to the solvent front) and the observation of the spot colour. The glucose, gluconate, 2KGA and 5KGA appeared as dark blue, pink, brown and dark purple spots, respectively. Solutions of glucose, gluconate, 2-keto gluconate and 5-keto gluconate adjusted at $100 \mathrm{mM}$ were used as standard. In addition, gluconic acid was also quantified using an enzymatic bioassay (kit 10428191035 from r-biopharm/Roche), according to the manufacturer's instructions. 
Picard et al.

Screening of the Tn5-pOT182 mutant library. A first screening of the mutant library was done in microplates using liquid ABm medium supplemented with tetracycline. After 3-days culture, part of the cell suspension was spotted using a 96-well replicator on : i) solid TriCalcium Phosphate (TCP) to determine the MW ability of each Tn5-mutant and ii) modified liquid TCP medium (TCPm) to determine their acidification ability. These two bioassays are commonly used to determine the mineral weathering potential of bacterial strains (Calvaruso et al. 2007; Lepleux et al. 2013; Uroz et al. 2009b; Colin et al. 2017). In addition, the homogeneity of the $\mathrm{Ca}_{3}\left(\mathrm{PO}_{4}\right)_{2}$ in the TCP assays allow for a high throughput screening of mutant libraries. On the contrary, biotite is a heterogeneous material requiring important replication of the assay, making its use incompatible with a first screening of the mutant libraries. The solid TCP medium is composed per litter of : $\mathrm{NH}_{4} \mathrm{Cl} 5 \mathrm{~g}$; $\mathrm{NaCl} 1 \mathrm{~g}$; $\mathrm{MgSO}_{4} 1 \mathrm{~g}$; Glucose $10 \mathrm{~g} ; \mathrm{Ca}_{3}\left(\mathrm{PO}_{4}\right)_{2} 4 \mathrm{~g}$ and $16 \mathrm{~g}$ of agar $(\mathrm{pH} 6.5)$. After incubation at $25^{\circ} \mathrm{C}$ for 7 days, the diameters of colonies and the diameter of discoloration zone (halo) were measured to determine the ability of each Tn5-mutant to solubilize inorganic phosphorous. The TCPm medium is modified version of the TCP devoid of $\mathrm{Ca}_{3}\left(\mathrm{PO}_{4}\right)_{2}$. The $\mathrm{Ca}_{3}\left(\mathrm{PO}_{4}\right)_{2}$ was removed from the medium to allow a better determination of the protons produced. The $\mathrm{pH}$ determination was performed after a 3-day incubation time. The supernatant was recovered by centrifugation $(8,000 \mathrm{~g}$ for $15 \mathrm{~min})$ and a volume of $180 \mu \mathrm{l}$ was transferred to new microplates containing $20 \mu \mathrm{l}$ of $\mathrm{pH}$ indicator (bromocresol green solution ; $1 \mathrm{~g} / \mathrm{l}$ ), according to Uroz et al. (2007). The $\mathrm{pH}$ of the supernatant was determined at $595 \mathrm{~nm}$ using an automatic microplate reader (Bio-Rad, model iMark) and converted in $\mathrm{pH}$ values using a calibration curve (Uroz et al. 2007).

Functional assays done on Tn5-OT182 mutants impaired in their MW ability. After the first step of screening, all the Tn5-OT182 mutants presenting a significantly reduced halo of 
Picard et al.

solubilisation on solid TCP and/or a $\mathrm{pH}$ value significantly higher than the WT strain were tested in a calibrated way on different bioassays in order to generate quantitative and comparable data. The recovered Tn5-mutants were cultivated overnight in liquid LBm medium supplemented with tetracycline. The WT strain was used as a positive control. Ten milliliters of each culture was washed three times with sterile MQ-water to eliminate all medium traces. The absorbance at $595 \mathrm{~nm}$ of each resulting suspension was then adjusted at $0.95 \pm 0.03$

\section{Phosphate solubilisation and solution acidification}

Ten microliters of each calibrated suspension were then dropped in triplicates on the surface of the solid TriCalcium Phosphate (TCP) and in microplates containing the modified liquid TCP medium (TCPm). Measures of $\mathrm{P}$ solubilisation and of acidification were performed as described above (Colin et al. 2017).

\section{Biotite dissolution}

Five hundred microliters of the calibrated suspension of each strain was transferred into sterile glass tubes containing $4.5 \mathrm{ml}$ of $\mathrm{BHm}$ medium $\left(20 \mathrm{mg} / \mathrm{l} \mathrm{KCl} ; 150 \mathrm{mg} / 1 \mathrm{MgSO} 4,7 \mathrm{H}_{2} \mathrm{O}\right.$; $80 \mathrm{mg} / 1 \mathrm{NaH}_{2} \mathrm{PO}_{4}, 2 \mathrm{H}_{2} \mathrm{O} ; 90 \mathrm{mg} / 1 \mathrm{Na}_{2} \mathrm{HPO}_{4}, 2 \mathrm{H}_{2} \mathrm{O} ; 65 \mathrm{mg} / \mathrm{l}\left(\mathrm{NH}_{4}\right)_{2} \mathrm{SO} 4,100 \mathrm{mg} / 1 \mathrm{KNO}{ }_{3} ; 20$ $\left.\mathrm{mg} / 1 \mathrm{CaCl}_{2}\right)$ buffered at $\mathrm{pH} 6.5$ and supplemented with glucose $(2 \mathrm{~g} / \mathrm{l})$ and $100 \mathrm{mg}$ of sterile biotite particles.

The biotite was obtained from Bancroft (Canada) and is a 2:1 phyllosilicate frequently found in acidic forest soils. This mineral holds $\mathrm{K}, \mathrm{Mg}$, and $\mathrm{Fe}$ nutrients. It is a pure homogeneous mineral, and its composition is as follows: $410.1 \mathrm{~g} / \mathrm{kg} \mathrm{SiO} 2,109 \mathrm{~g} / \mathrm{kg} \mathrm{Al}_{2} \mathrm{O}_{3}$, $22.1 \mathrm{~g} / \mathrm{kg} \mathrm{Fe}{ }_{2} \mathrm{O}_{3}, 100.5 \mathrm{~g} / \mathrm{kg} \mathrm{FeO}, 2.7 \mathrm{~g} / \mathrm{kg} \mathrm{MnO}, 189 \mathrm{~g} / \mathrm{kg} \mathrm{MgO}, 4.1 \mathrm{~g} / \mathrm{kg} \mathrm{Na} 2 \mathrm{O}, 94.6 \mathrm{~g} / \mathrm{kg}$ $\mathrm{K}_{2} \mathrm{O}, 22.8 \mathrm{~g} / \mathrm{kg} \mathrm{TiO} 2,44.2 \mathrm{~g} / \mathrm{kg} \mathrm{F}$, and $0.8 \mathrm{~g} / \mathrm{kg} \mathrm{Zn}$. Its structural formula is $\left(\mathrm{Si}_{3} \mathrm{Al}_{1}\right)\left(\mathrm{Fe}^{3+}{ }_{0.12}\right.$ 
Picard et al.

$\left.\mathrm{Fe}^{2+}{ }_{0.61} \mathrm{Mg}_{2.06} \mathrm{Mn}_{0.02} \mathrm{Ti}_{0.13}\right)$ and $\mathrm{K}_{0.88} \mathrm{Na}_{0.06} \mathrm{O}_{10}\left(\mathrm{OH}_{0.98} \mathrm{~F}_{1.02}\right)$. The particle size of biotite was calibrated from 200 to $500 \mu \mathrm{m}$.

Before use, all glass was rinsed with chloridric acid and deionised water to remove any chemical traces. The tubes containing the culture medium with biotite were then sterilised by autoclaving at $121^{\circ} \mathrm{C}$. After seven days of incubation at $25^{\circ} \mathrm{C}(200 \mathrm{rpm}), 1 \mathrm{ml}$ of supernatant was sampled and centrifuged at $11,000 \mathrm{~g}$ for $15 \mathrm{~min}$ and filtered at $0.22 \mu \mathrm{m}$. Quantification of the iron released from biotite and of the acidification of the medium were determined by adding $180 \mu \mathrm{l}$ of supernatant of each culture in a new microplate containing $20 \mu \mathrm{l}$ of ferrospectral or bromocresol green, respectively (Uroz et al. 2007). The absorbance of these suspensions was measured at $595 \mathrm{~nm}$ and the data transformed in $\mathrm{pH}$ and iron concentrations using the colorimetric assays described above to determine the MW potential of each Tn5pOT182 mutant.

In addition, model chelating (citric acid) or acidifying (hydrochloric acid) molecules were used as control in the same mineral weathering assay. Serial dilutions of citric acid $\left(10^{-3} \mathrm{M}\right.$; $\mathrm{pH}$ adjusted to 6 to 2 ) and hydrochloric acid (concentration adjusted to be at $\mathrm{pH} 6$ to 2 ) were performed in BHm medium and incubated in the same condition than the bacterial strains tested as described in Uroz et al. 2007.

\section{Cytochrome oxydase test}

To test if mutants are affected in their cytochrome oxydase activity, $100 \mu 1$ of the calibrated cell suspension were spotted on a filter paper and flooded in a $1 \%$ Tetramethyl-pphenylenediamine (TMPD) solution during $10 \mathrm{~min}$. After this incubation period, the filter paper was dried 30s and inspected. In the case of a positive reaction, the filter paper becomes purple, while in the case of a negative reaction it remains white (Kovacs, 1956). 
Picard et al.

Glucose dehydrogenase (GDH) test

To test if mutants were affected in their GDH activity, the test of Matsushita and Ameyama (1982) was used on the calibrated cell suspension (CS) or on cell crude extract (CE). The cell crude extract was obtained by ultra sonication treatment (Vibra-Cell; Sonics, Newtown USA) of the CS, followed by a centrifugation at $7000 \mathrm{~g}(15 \mathrm{~min})$ to remove intact cells and a filtration at $0.22 \mu \mathrm{m}$. A volume of $100 \mu 1$ of CS or CE was incubated with $100 \mu 1$ of Tris-HCL (50mM; pH:7.5), $10 \mu \mathrm{l}$ of 2,6-dichlorophenolindophenol (DCIP; $6.7 \mathrm{mM}), 10 \mu 1$ of phenazine methosulfate (PMS; $20 \mathrm{mM}), 10 \mu 1$ of $(\mathrm{FAD} ; 600 \mu \mathrm{M}), 100 \mu 1$ of glucose $(1 \mathrm{M})$, and MQ water in a final volume of $300 \mu \mathrm{L}$. The reaction is initiated by the addition of D-glucose. GDH activity is measured at $600 \mathrm{~nm}$ in microplate reader (Tecan infinite M200 pro). Controls without glucose and/or FAD were performed. In addition, a control without the CS or CE was performed for each of the condition tested (+/- FAD; +/- Glucose).

\section{Growth assay and carbon substrate use}

To determine whether the mutants were impaired in their growth ability, tests were performed under nutrient-rich and nutrient-poor conditions. For the nutrient-rich condition, $10 \mu 1$ of each calibrated suspension (WT and mutants) were added to $190 \mu \mathrm{l}$ of liquid LB medium in a microplate. The microplate was incubated at $25^{\circ} \mathrm{C}$ and orbital shaking during 4 days in a microplate reader (Tecan infinite M200 pro). The absorbance was measured at $600 \mathrm{~nm}$ each 3 hour. For the nutrient-poor condition, $10 \mu \mathrm{l}$ of each calibrated suspension was added to $190 \mu 1$ of liquid BHm medium amended with a source of carbon $(2 \mathrm{~g} / \mathrm{l})$. The carbon sources used were glucose, gluconic acid, 2-Keto-gluconate, 5-Keto-gluconate. After 5 days of incubation at $25^{\circ} \mathrm{C}$, the $\mathrm{pH}$ was measured with bromocresol green as described above and the growth was measured at $595 \mathrm{~nm}$. 
Picard et al.

Bioinformatic analyses. Genome analysis was performed using NCBI and MAGE (Vallenet et al. 2009). Homology search analysis and alignment were performed with BLAST (BlastN and BlastP ; Altschul et al. 1997). Localization of the Tn5-OT182 insertion was done on MAGE. A research of Twin Arginine Translocation (TAT) signal carrying proteins was done using the predictor servers Tatfind (Dilks et al. 2003) and TatP 1.0 (Bendtsen et al. 2005). The two proteins lists were assembled and analysed. Analyses of the pfam domains and of the conservation of the GdhL subunit sequence were done using pfam ( El-Gebali et al. 2019) and Seaview (version 4.5.4) (Gouy et al. 2010). To study the conservation of the GdhL sequence, a set of 22 different genera or species related to Collimonas and available on international databases were analysed among them, 11 were assigned to Collimonas genus (Collimonas sp. PA-H2, OK242, OK307 and OK607, C. fungivorans Ter331 and Ter6, C. arenae Cal35, Ter10 and Ter282, C. pratensis Ter91, Ter291). Other genera taxonomically close to Collimonas were chosen : 2 belonging to the Glaciimonas genus (Glaciimonas sp. PCH181 and GS1), one to Janthinobacterium, 2 to Herbaspirillum (H. rubrisubalbicans and $H$. seropidecae) and one to Burkholderia cepacia. In addition, we selected the sequences of the large subunit of a set of GMC oxidoreductase which function was demonstrated: a gluconate dehydrogenase (GADH ; BAH80545.1) and a sorbitol dehydrogenase (BAD60913.1) from Gluconobacter frateurii (Toyama et al. 2005; Saichana et al. 2009), a fructose dehydrogenase large subunit of Gluconobacter japonicas (BAM93252.1) (Kawai et al. 2013). We also considered the sequences of the large subunit of a putative sorbitol dehydrogenase from Gluconobacter oxydans H24 (AFW02570.1) and a dehydrogenase subunit from Pantoea agglomerans (AAF21261.1). The same genome resources were also used to recover the pqqgenes as well as the pqq-dependent enzymes. 
Picard et al.

Statistical analysis. Statistical analyses were performed in R software. Data shown were means of, at least, triplicates. Differences between sample's means were analysed by ANOVA and Tukey HSD tests.

Nucleotide sequence accession number. The nucleotide sequence reported in this paper are related to the genome sequence of the strain PMB3(1), which has been deposited in the GenBank database under accession no. WXXL00000000.

\section{RESULTS}

\section{1) Genomic and physiological characterization}

At the genomic level, the detailed analysis of the genome of strain PMB3(1) did not permit to evidence any PQQ-dependent GDH nor the presence of the PQQ cofactor encoding genes. Similarly, none of the Collimonas genome available in the international databases (i.e., Collimonas sp. PA-H2, C. fungivorans Ter331 and Ter6, C. arenae Cal35, Ter10 and Ter282, C. pratensis Ter91, Ter291) possess PQQ encoding genes and/or PQQ-dependent enzymes, suggesting that alternative MW pathways exist in collimonads.

At the chemical level, high concentrations of gluconic acid were detected in the supernatant of cultures of strain PMB3(1) done with glucose (Table 2), evidencing that this strain was capable of converting glucose to gluconic acid (GA) through an alternative, PQQ-independent pathway. Noticeably, the thin layer chromatography analyses confirmed the large production of gluconic acid, but also a weak production of 2 keto-gluconic acid (2KGA) by strain PMB3(1) as evidenced by the comparison with the migration retention factor (Rf) and the colour of the synthetic GA and 2KGA controls used (Fig. 1; Table 2). A kinetic analysis confirmed the continuous accumulation of GA, while $2 \mathrm{KGA}$ was hardly detectable. Interestingly, the growth assays done in minimal medium supplemented with a single source 
Picard et al.

of carbon (i.e., glucose, GA, 2KGA or 5KGA) confirmed that glucose, GA and 2KGA were used as carbon source by strain PMB3(1), but not 5KGA. Among them, glucose was the sole carbon which metabolism allowed an acidification of the culture supernatant $(\mathrm{pH}=3.5)$, while the $\mathrm{pH}$ did not change in presence of GA and 2KGA (i.e., $\mathrm{pH}=6.2$ ).

\section{2) Isolation of mutants affected in the ability to solubilize inorganic phosphorous}

The first high throughput screening of the mutant library allowed us to recover a total of 4 mutants (i.e., 25(10F), 31(11B), 34(11H), 59(7B)) impaired in their ability to solubilize inorganic phosphorous (Pi).

The use of the calibrated procedure (see materials and methods) confirmed that these 4 mutants were significantly altered in their ability to solubilize $\mathrm{Pi}(\mathrm{P}<0.05)$. Based on this second screening, three of these mutants, 25(10F), 31(11B), 34(11H), did not present a solubilisation halo (Table 2). For the mutant 59(7B), a reduction of $34 \%$ of the halo diameter was observed compared to the WT strain (halo_WT: $0.79 \mathrm{~cm} \pm 0.04$ vs halo_59(7B): $0.52 \mathrm{~cm}$ \pm 0.1 ). All these mutants and WT presented similar colony diameters. The acidification assay revealed that the ability of mutants $25(10 \mathrm{~F}), 31(11 \mathrm{~B})$ and $34(11 \mathrm{H})$ to acidify was significantly reduced $(\mathrm{P}<0.05)$. Indeed, while the WT strain and mutant 59(7B) acidified the medium from the initial $\mathrm{pH} 6.5$ to $\mathrm{pH} 3.7$ in three days, mutants 25(10F), 31(11B), 34(11H) acidified the medium only to $c . a . \mathrm{pH} 4.7$ (average value).

\section{3) Ability to weather biotite}

The ability to weather a complex mineral was tested only for the three mutants totally impaired in their ability to solubilize Pi (i.e., 25(10F), 31(11B), 34(11H)) as well as for the WT strain (Fig. 2). After a 7-day incubation in presence of glucose as carbon source, the WT strain was able to release $1.29 \pm 0.13 \mathrm{mg} / \mathrm{l}$ of iron in the solution. In comparison, the three 
Picard et al.

mutants $25(10 \mathrm{~F}), 31(11 \mathrm{~B})$ and $34(11 \mathrm{H})$ released significantly less iron $(0.32 \pm 0.08,0.54 \pm$ 0.04 and $0.39 \pm 0.02 \mathrm{mg} / \mathrm{l}$, respectively) $(\mathrm{P}<0.05)$ (Fig. 2A). Those values corresponded to a maximal reduction of $75 \%$ for mutant $25(10 \mathrm{~F})$ and a minimal reduction of $58 \%$ for mutant 31(11B) compared to the WT strain. After the 7-day incubation, the WT strain decreased the $\mathrm{pH}$ of the culture supernatant to $\mathrm{pH}=3.3 \pm 0.1$, while the mutants reached significantly higher value (4.3 to $4.5 ; \mathrm{P}<0.05$ ) (Fig. $2 \mathrm{~B}$ ). The co-visualization of the quantity of iron released from biotite and of the $\mathrm{pH}$ of the supernatant confirmed the strong perturbation of the mineral weathering ability of the mutants compared to the WT strain (Fig. 2C).

\section{4) Sequence analyses of the genomic region for the different mutants}

The genomic region flanking the plasposon insertion of each mutant was isolated by selfcloning using the plasposon rescue method. For each mutant, 3 independent clones were recovered, sequenced and blasted against the genome sequence of strain PMB3(1). This revealed a single genomic region per mutant, demonstrating a unique plasposon insertion event in each of the mutants considered [25(10F), 31(11B), 34(11H), 59(7B)]. The sequences were also blasted against nucleic acid and protein databases of the NCBI for homologous sequences.

In mutant 25(10F), the plasposon is inserted in a gene we named $g d h C$ (NKI70796.1). This gene presented high homology with a cytochrome c subunit of a Glucose/Gluconate/Sorbitol 2-dehydrogenase (Fig. 3, Table 3). Pfam analysis highlighted two conserved domains (cytochrome c from 36 to 137 aa/ cytochrome CBB3 from 322 to 406 aa ; e-value $=6.6 \mathrm{e}-07$ 15.4e-10, respectively) corresponding to a cytochrome c oxidase protein. This gene is preceded by two genes presenting sequence homology with subunits of a Glucose/Methanol/Choline (GMC) oxidoreductase. The first one presented high sequence homology $(98 \%$ ) with the large subunit (NKI70795.1; gdhL) belonging to the FAD 
Picard et al.

flavoprotein oxidoreductases, while the next gene presented high homology $(80 \%)$ with the gamma subunit (NKI70794.1; $g d h S)$ of a Sorbitol/Glucose/2-Keto-D-Gluconate dehydrogenase. Pfam analysis revealed that this gamma subunit presented high sequence similarities with the FAD-Sorbitol dehydrogenase family protein $\left(\mathrm{e}\right.$-value $\left.=2.5 .10^{-48}\right)$ and carried a potential TAT-signal.

In mutant $31(11 \mathrm{~B})$, the plasposon is inserted in a genomic region presenting high sequence homology with a resB homologous gene (NKI71673.1;94\% identity with cytochrome c biogenesis protein ResB in Collimonas sp. PA-H2) (Fig. 3, Table S1). This gene belongs to a genetic structure composed of 3 genes (NKI71672.1; NKI71673.1; NKI71674.1) involved in cytochrome c biogenesis /maturation. Among them, gene NKI71672.1 codes for a cytochrome c4 immature protein and gene NKI71673.1 is gene resC coding for a cytochrome c biogenesis protein. In the vicinity of the resB gene, two other genes, yed $Y$ and yedZ (NKI71676.1, NKI71677.1), presenting high sequence homology with a sulfite oxidase were detected.

In mutant $34(11 \mathrm{H})$, the plasposon is inserted in a genomic region presenting high sequence homology with the Twin Arginine Translocation pathway (TAT) operon (tatABC). The insertion was localized between the gene tatB (NKI71758.1; 93\% identity with Secindependent protein translocase subunit TatB in Collimonas sp. PA-H2) and tatC (NKI71759.1; 95\% of identity with the twin-arginine translocase subunit TatC in Collimonas sp. PA-H2) (Fig. 3, Table S2).

In mutant 59(7B), the plasposon is inserted in the gene int (NKI72639.1) presenting high sequence homology with an apolipoprotein $\mathrm{N}$-acyltransferase $(92 \%$ of identity with the apolipoprotein $\mathrm{N}$-acyltransferase of Collimonas sp. PA-H2) (Fig. 3, Table S3). This enzyme is responsible for the last step of lipoprotein maturation. In the vicinity of this gene, 5 genes involved in metabolism and two genes involved in information storage and processing were identified according to their COG class. 
Picard et al.

5) Identification of TAT-dependent proteins

Due to the localization of the plasposon insertion of mutant $34(11 \mathrm{H})$ in the TAT system region, a bioinformatic analysis was done to identify all proteins presenting a putative TAT signal in the genome of strain PMB3(1). Indeed, the perturbation of the MW ability may be related to a protein carried by the TAT system. This screening allowed the identification of 74 TAT-proteins related to different Clusters of Orthologous Groups (COG) (metabolism, cellular processes and signalling, information storage and processing, or poorly characterized (Table S4; Fig. S1). Among them, we noticeably identified the protein $g d h S$ that corresponds to the gamma subunit of the Sorbitol/Glucose/2-Keto-D-Gluconate dehydrogenase gene (NKI70794.1). This gene is in an operon along with gene $g d h C$ (i.e., cytochrome subunit of the Sorbitol/Glucose/2-Keto-D-Gluconate dehydrogenase) interrupted in mutant 25(10F) (see fig. 3) Other enzymes related to putative alkaline phosphatases (i.e., PhoD like, NKI71510.1 and NKI72605.1), involved in cytochrome c biogenesis (NKI72023.1) or presenting an oxidoreductase activity (NKI71676.1) were also identified in the list of TAT-proteins.

\section{6) Functional and physiological characterization of mutants 25(10F), 31(11B) and 34(11H)} Cytochrome activity

As mutants 25(10F) and 31(11B) were affected on genes encoding a cytochrome subunit or involved in the biogenesis of cytochrome $\mathrm{c}$, a cytochrome oxidase test was performed on all mutants. This qualitative test based on the oxidation of Tetramethyl-p-phenylene diamine (TMPD) revealed that the three mutants formed a purple pigment as the WT strain (Table 2), revealing that the cytochrome c oxidase of the strain PMB3(1) was still functional in all the mutants. This result highlights that strain PMB3(1) possesses several cytochrome $\mathrm{c}$ biogenesis 
Picard et al.

systems independent on the resB/resC system interrupted in mutant $31(11 \mathrm{~B})$. Indeed, a genome analysis revealed that the strain PMB3(1) possesses two cytochrome biogenesis loci.

\section{Detection and quantification of organic acids}

Ionic chromatography analyses permitted to identify the main acids produced (i.e., Gluconate, oxalate, pyruvate, formate, and succinate) by the WT strain and mutants in presence of glucose (Table 2). Gluconate was the major organic acid detected in the WT culture supernatant, reaching a concentration of $878.7 \pm 3.3 \mathrm{mg} / \mathrm{l}$, while all other organic acids are present at very low concentrations (pyruvate: $2.87 \mathrm{mg} / \mathrm{l}$; succinate: $0.07 \mathrm{mg} / \mathrm{l}$ ). Noticeably, gluconate was not detected in any of the supernatants from the 3 mutants (i.e., mutants 25(10F), 31(11B) and 34(11H); Table 2). Amongst other organics, only pyruvate presented significant differences between the WT strain and mutants, but with very low concentrations (WT: $2.87 \pm 0.63 \mathrm{mg} / \mathrm{l} ; 25(10 \mathrm{~F}): 1.08 \pm 0.03 \mathrm{mg} / \mathrm{l} ; 31(11 \mathrm{~B}): 1.55 \pm 0.23 \mathrm{mg} / \mathrm{l}$ and $34(11 \mathrm{H})$ : $0.11 \pm 0.06 \mathrm{mg} / \mathrm{l})(\mathrm{P}<0.05)$.

\section{Growth in rich $(L B)$ medium}

To get a better understanding of the importance of the gene(s) interrupted in the different mutants, their growth was monitored for 120 hours in LB medium (Fig. 4; Table 2). No difference between the WT and the 25(10F) mutant was observed. Indeed, the growth rate $\left(0.09 \pm 0.02 \mathrm{~h}^{-1} ; \mathrm{P}<0.01\right)$, the lag time $(\mathrm{ca} .10 \mathrm{~h})$, the maximal growth yield $\left(\mathrm{OD}_{595 \mathrm{~nm}}\right.$ of $1.20 \pm$ 0.05) as well as the time necessary to reach the stationary phase for the WT and mutant 25(10F) (i.e., $40 \mathrm{~h})$ were similar. In contrast, mutants $31(11 \mathrm{~B})$ and $34(11 \mathrm{H})$ differed significantly from the WT strain. Mutant 31(11B) presented a growth rate of $0.06 \pm 0.01 \mathrm{~h}^{-1}$, a lag phase of $25 \mathrm{~h}$, a maximal growth yield $\left(\mathrm{OD}_{595 \mathrm{~nm}}\right)$ of $0.95 \pm 0.08$ and it required $50 \mathrm{~h}$ to reach the stationary phase. Mutant $34(11 \mathrm{H})$ presented the lowest growth rate of $0.02 \pm 0.01 \mathrm{~h}^{-}$ 
Picard et al.

$488^{1}$, a maximal growth yield $\left(\mathrm{OD}_{595 \mathrm{~nm}}\right)$ of $1.08 \pm 0.08$ and it required $120 \mathrm{~h}$ to reach this maximum.

Impact of the carbon source on the acidification process

As acidification plays an important role in the mineral weathering process by strain PMB3(1), several carbon sources coming from the metabolism of glucose (i.e., gluconate, 2KGA, 5KGA) were tested in minimal medium (BHm) (Fig. 5). Contrary to the strong acidification observed with glucose, these growth assays revealed no difference of $\mathrm{pH}$

between the WT and mutant strains when they were cultivated in minimal medium amended with glucose derivatives such as $\mathrm{GA}$ or $2 \mathrm{KGA}\left(\mathrm{pH}_{\mathrm{WT}}=\mathrm{pHmutant}=6.2\right)$. No growth was observed with 5KGA.

\section{7) Complementation analysis of the mutants}

To confirm the involvement of the interrupted genes identified in the different mutants (i.e., 25(10F), 31(11B) and $34(11 \mathrm{H})$ ) in the MW ability of strain PMB3(1), a functional complementation was performed. For each mutant, the native gene(s) under a constitutive promoter was cloned in the pBBR1MCS-2 vector. These constructions were then transformed in the corresponding mutant and tested with the same set of functional assays as described above. Noticeably, the quantitative assays performed on solid TCP medium revealed that the complemented mutants $25(10 \mathrm{~F})(\mathrm{pB} 2-g d h C)$ and $34(11 \mathrm{H})(\mathrm{pB} 2$-tatABC) recovered fully their mineral weathering ability to WT effectiveness (Table 2$)$. The mutant $31(11 \mathrm{~B})(\mathrm{pB} 2-\mathrm{res} B)$ was restored in its ability to weather mineral, but presented a slightly lower efficiency than the WT strain, when harbouring gene resB on the pBBR1MCS-2 plasmid. Regarding acidification, upon complementation $\mathrm{pH}$ was further reduced from $\mathrm{pH} 5.1 \pm 0.1$ observed in the mutants to $4.4 \pm 0.1$ in the complemented mutants after 3 days, which was not 
Picard et al.

significantly different from that observed with the WT strain harbouring the empty vector pBBR1MCS2 $(4.3 \pm 0.1)$. In addition, the restoration of the glucose dehydrogenase activity was observed in the complemented mutants. Last, complementation restored growth of all mutants (Fig. 4).

\section{8) Bioinformatic properties and conservation of GMC oxidoreductases in the collimonads} and related genera

For bacteria carrying a glucose dehydrogenase enzyme of the GMC oxidoreductase family, the conversion of glucose to gluconic acid is mainly performed by the large subunit (i.e., $g d h L$ ) of the enzyme (Yamaoka et al. 2008). In this context, bioinformatic analyses were performed on this subunit to analyse its properties and its conservation among collimonads and related taxa.

In strain PMB3(1), this approach allowed to identify a single GMC oxidoreductase organized in three subunits and corresponding to the genomic region described above for mutant $25(10 \mathrm{~F})$. A second homologous of the large subunit (GdhL) was also identified in strain PMB3(1), but with a low identity (20\%). Contrary to the GMC oxidoreductase, this homologue is organized as a single unit (i.e., one gene) and encodes a putative choline dehydrogenase. The pfam analysis done on the sequence of the large subunit of the strain PMB3(1) evidenced the presence of a Rossmann-like domain (amino acid 11 to 41; e-value = 2.0e-5) and two GMC oxidoreductase domains (domain C: 405 to 525 , e-value 1.5e-18; domain $\mathrm{N}$ : 176 to $318,1.5 \mathrm{e}-5)$, supporting by this way the function attributed to the gene identified in our study (i.e., a Glucose dehydrogenase from the GMC oxidoreductase family) (Fig. S2). Notably, all the GMC oxidoreductases described in the literature present the 3 domains detected (Rossmann, GMC_N, GMC_C) and all are specifically associated to enzymes binding FAD as cofactor (i.e., gluconate dehydrogenase, GADH; glucose 
Picard et al.

dehydrogenase, GDH; fructose dehydrogenase, FDH; sorbitol dehydrogenase, SDH) (Kataoka et al. 2015; Toyama et al. 2005).

The comparison of homologous sequences from the available Collimonas genome sequences revealed a very good conservation of the different domains (Fig. S3). In the putative FAD domain, only two positions on a total of 31 varied among the collimonads (Fig. S2). In the GMC_C domain, 10 positions on a total of 86 varied, while 16 positions on a total of 121 varied in the GMC_N domain (Fig. S2). Beside these pfam domains, we also detected in the large subunit sequence of strain PMB3(1), the cysteine-rich region (cys208, cyst214, cys218 in our alignment; Fig. S2) identified by Shiota et al. (2016) as specific of the FADdependent dehydrogenases. This region is constituted by three conserved cysteine (Cys) residues (CCGNNNCMPICP), all conserved in the Collimonas genomes considered. This particular site constitutes an iron-sulfur cluster essential for electron transfer from FAD to the cytochrome c subunit (Shiota et al. 2016).

When the sequence comparison integrated neighbouring genera, it revealed a good conservation of the large subunit sequence among the taxa tested and a stronger relatedness of Janthinobacterium and Glaciimonas with Collimonas. In contrast, Herbaspirillum presented important variations (Fig. S3). The sequence of the GdhL protein of strain PMB3(1) presented ca. $90 \%$ of identity with that of strains PCH181 and GS1 of Glaciimonas sp., $80 \%$ with that of Janthinobacterium and only $50 \%$ with that of Herbaspirillum seropedicae and $H$. rubrisubalbicans. The low relatedness of the GdhL of Herbaspirillum was also visible in the sequence alignment, especially in the domain GMC_C.

Last, a sequence comparison between the large subunit of strain PMB3(1) and the large subunit of FAD-dependent dehydrogenases for which the function and/or the FADdependence were experimentally demonstrated (i.e., a GADH from Gluconobacter frateurii, two SDHs from Gluconobacter oxydans and G. frateurii, a FDH from Gluconobacter 
Picard et al.

japonicas and a GDH from Burkholderia cepacia) or suspected (choline dehydrogenase (CDH) from Pantoea agglomerans) was performed (Fig. S3). This analysis revealed that the most distantly related sequence was the GADH. The positions on the phylogenetic tree are supported by the strong sequence variations observed in the sequence alignment. The large subunit sequence of strain PMB3(1) appeared also poorly related to the FDH and SDH. The stronger relationship was observed with the glucose dehydrogenase (GDH) from Burkholderia cepacia (Tsuya et al. 2006).

\section{DISCUSSION}

The ability to weather minerals was evidenced for a broad range of bacterial genera, but the genes involved have been poorly investigated and characterized. To date, the main system described is related to the PQQ-dependent glucose dehydrogenases (PQQ-GDH), which allows the production of protons and gluconic acid. The role of such enzymes and the related pqq genes (i.e., pqqABCDEF) in the solubilisation of highly weatherable minerals (i.e., $\mathrm{Pi}$ ) was reported in several studies (Goldstein, 1995; Goldstein et al. 2003; Babu-Khan et al. 1995), but only recently for a complex mineral (i.e., biotite; Wang et al. 2020). In this study, we investigated the molecular mechanisms and the genes explaining the high MW effectiveness of strain PMB3(1) of Collimonas as well as their relative conservation among collimonads.

Collimonads have been isolated from various nutrient-poor environments (i.e., sand dune, forests soil) and in fungal rich habitats (i.e., mycorrhizosphere) (Colin et al. 2017; Uroz et al. 2007; Lepleux et al. 2012). They are recognized as particularly effective at mobilizing nutrients using fungal derived metabolites such as glucose, trehalose, mannitol (Uroz et al. 2009b). The genome analysis performed in this study reveals that none of the sequenced Collimonas to date possess the canonical $p q q$ biosynthesis genes nor PQQ-dependent 
Picard et al.

enzymes, meaning that alternative mechanisms to the PQQ-dependent pathway are involved in their MW ability. Those results confirmed the observations made on the Ter Collimonas strains (Ter331, Ter14, Ter6, Ter91 or Ter10; Mela et al. 2012) or on strain PMB3(1) (Picard et al. 2020). In this study, we confirmed that strain PMB3(1) is very effective at weathering and at producing gluconic acid, and we showed for the first time that at least a part of this gluconic acid is converted to 2-keto-gluconic acid (2KGA), evidencing the presence of a glucose dehydrogenase (GDH) activity and of a gluconate dehydrogenase (GADH) activity. Such conversion of glucose to gluconic acid and then to $2 \mathrm{KGA}$ corresponds to the direct oxidative pathway described by Ebert et al. (2011). The 2KGA is then converted into 6-Pgluconate by a 2-keto gluconate kinase and a 2-keto gluconate 6-phosphate reductase prior to entering the Pentose pathway or the Entner-Doudoroff pathway (Ebert et al. 2011). Beside its capability to produce gluconic and 2-keto-gluconic acids, we demonstrated that strain PMB3(1) is capable of metabolizing these two acids, without acidification of the solution. No growth was observed with the 5-keto-gluconic acid. The ability to produce GA and 2KGA is well conserved among Gram-negative bacteria, but the production of 5KGA or 2,5KGA is more specific to acetic bacteria such as Acetobacter or Gluconobacter (Sützl et al. 2019). Bacteria producing $\mathrm{GA}$ and $2 \mathrm{KGA}$ have been described as being more effective at solubilizing calcium phosphate than other bacteria (Babu-Khan et al. 1995).

A focus on the genomic region flanking the plasposon insertion in mutant $25(10 \mathrm{~F})$ allowed a better understanding of the link between the 3 weathering null mutants, though they were geographically distant and apparently unrelated. We identified a PQQ-independent enzyme presenting high homology with Glucose/Methanol/Choline (GMC) oxidoreductases (Sützl et al. 2019; Cavener, 1992). The GMC superfamily encompasses a wide variety of FADdependent oxidoreductases (e.g., glucose oxidase (GO), glucose dehydrogenase (GDH), alcohol oxidase $(\mathrm{AO})$, cellobiose dehydrogenase $(\mathrm{CDH})$ ) that are present in both prokaryotic 
Picard et al.

and eukaryotic domains (Sützl et al. 2019; Zamocký et al. 2004). They are composed of three subunits encoding a small subunit, a large subunit, and a cytochrome c subunit (Sützl et al. 2019; Cavener, 1992), corresponding exactly in term of organization (small subunit: $g d h S$; large subunit: $g d h L$ and cytochrome subunit: $g d h C$ ) and sequence homology to the genomic region impacted in mutant 25(10F). The large subunit of strain PMB3(1) is characterized by several domains according to pfam analysis (a FAD domain and two GMC oxidoreductase domains $(\mathrm{N}$ and $\mathrm{C})$ ) and the presence of a cysteine rich region. This cysteine rich region was shown to be conserved in the catalytic large subunit of FAD-dependent dehydrogenases (Shiota et al. 2016). While we were able to demonstrate the GDH activity and the production of gluconic acid by strain PMB3(1), testing experimentally the FAD dependence of the GDH activity would require the purification of the three subunits in a functional form, which was not possible in our labs. A FAD dependence test performed on lyzed cells was inconclusive. The known FAD-dependent GDHs are involved in the oxidation of different substrates including sugars, alcohols, cholesterol and choline and their conversion to the corresponding lactone. In presence of glucose, these enzymes allow the production of D-glucono-1,5lactone, which is then converted to gluconic acid through the action of a gluconolactonase or spontaneous hydrolysis (Ferri et al. 2011; Zamocky' et al. 2004). Strain PMB3(1) possesses several putative gluconolactonases (NKI70323.1, NKI67822.1, NKI72143.1) in its genome. Although additional experiments are required to support the different steps, we proposed here a hypothetical functional model of the main mechanisms used by strain PMB3(1) to weather minerals and linking the different mutants obtained in this study (Fig. 6).

To be functional GMC oxidoreductases also require a mature cytochrome c subunit and a small subunit. The maturation of the cytochrome $\mathrm{c}$ subunit is performed through the ResB and ResC system (Crow et al. 2005), which allows the translocation of the heme during cytochrome maturation (Kranz et al. 2009). Without the heme, the cytochrome c subunit is 
Picard et al.

not functional and does not permit electron transfer. Strain PMB3(1) possesses both ResB and ResC system and very interestingly the res $B$ gene is interrupted in our mutant 31(11B), likely interrupting the maturation of the cytochrome c subunit of the GDH identified. Notably, its activity was restored when a complementation in trans was done with the gene resB. The last small subunit of the GMC oxidoreductases is a protein required for the proper folding and secretion of the large subunit (Shiota et al. 2016; Yamaoka et al. 2008). Indeed, without a functional small subunit, the GDH of Burkholderia cepacia strain SM4 failed to perform the oxidation of its substrate (Yamaoka et al. 2008). The small subunit of strain PMB3(1) is also characterized by a TAT-signal. This particularity was also observed in various dehydrogenases organised in three subunits. This strongly suggests that in absence of translocation of the small subunit, the related FAD-dependent enzyme is not functional. Congruent with this hypothesis, Toyama et al. (2007) showed that the assembly of the different subunits of the FAD-GADH of Gluconobacter dioxyacetonicus was performed in the cytoplasm before the translocation through the TAT system and using the TAT signal of the small subunit. In addition, experimentations showed that TAT system allowed the translocation of folded proteins associated with their co-factor (Allen et al. 2002; Palmer and Berks, 2012). In this context, the TAT-signature of the PMB3(1) GdhS (i.e., the small subunit of the GDH) represents the link between the mutant $34(11 \mathrm{H})$ and the MW null phenotype. Besides the small subunit of the Glucose dehydrogenase (GdhS) of strain PMB3(1), several other TAT-exported proteins could also play a role in MW, such as those involved in cytochrome biogenesis, oxidoreduction or more especially in the hydrolysis of organic phosphate (Table S4) (Chhabra et al. 2013 ; Lidbury et al. 2016). However, the complete loss of MW activity in the other two mutants (i.e., 25(10F), 31(11B)) would not support this hypothesis. 
Picard et al.

The conservation of the MW ability among collimonads prompted us to determine the phylogenetic distribution of the GDH type identified in strain PMB3(1) in collimonads and closely related genera. The comparison done on the sequenced genomes of Collimonas $(C$. pratensis , $C$. arenae, $C$. fungivorans, $C$. sp.) revealed a good conservation of this GDH type as well as of the TAT system, and the absence of PQQ-dependent GDHs or the related $p q q$ biogenesis genes in collimonads. Such conservation of the PQQ-independent GDH identified from strain PMB3(1) was expected, as Collimonas are known to harbour important gene conservation among the different species described (Mela et al. 2012). The comparison done between the large subunit of the GDH of strain PMB3(1) and other dehydrogenases FADdependent in other taxa revealed that it was more strongly related to Glaciimonas, Janthinobacterium and Burkholderia than Herbaspirillum or Gluconobacter. The GDH of PMB3(1) presented higher homology with other alcohol dehydrogenases experimentally identified as sorbitol (FW02570.1), glucose (AAN39686.1) or fructose (BAM93252.1) dehydrogenases, all FAD-dependent. This relative proximity between different type of FADdependent dehydrogenases may be due to the low substrate specificity of some of these enzymes, which are capable of oxidizing different substrates, including glucose (Yamaoka et al. 2008). In contrast, the most distantly related FAD-dependent dehydrogenase of our analysis was the GADH (i.e., Gluconate DH; BAH80545.1) of Gluconobacter frateurii that converts gluconate to 2 ketogluconate. Beside the large subunit, the small and cytochrome subunits were also well conserved between collimonads and related taxa. The conservation of an homologous of the GDH of strain PMB3(1) in Glaciimonas and the presence of this taxa in nutrient-poor and rocky environments (i.e. the forest soil, alpine glaciers) (Udovičić et al. 2015) suggest that members of this genus are well adapted to oligotrophic conditions and capable of weathering minerals as are collimonads. Their MW ability remains to be tested. In contrast, important differences were found in the sequence of the GMC_C domain and the 
Picard et al.

Cys-rich region of the large subunit of Herbaspirillum, a genus reported as non- or poorlyeffective at weathering minerals (Uroz et al. 2009b). Beside the presence of a GMC oxidoreductase homologue, our genomic analyses revealed that some representative strains of the genus Burkholderia, Glaciimonas, Gluconobacter or Pantoea were also characterized by the presence of $p q q$-encoding genes as well as PQQ-dependent enzymes in their genome, but their ability to solubilize minerals is unknown. Such results reveal that bacteria can possess both PQQ-dependent and -independent GDH. Interestingly, a dual transcriptomic and proteomic approach done on another effective MW bacterial strain (i.e. strain PML1(12) of Caballeronia mineralivorans) harbouring both systems highlighted that a homologous GMC oxidoreductase was up-regulated in presence of biotite, while the $p q q$-related genes appeared poorly expressed and not regulated (Uroz et al. 2020). This GMC oxidoreductase presented high sequence homology with the FAD-dependent GDH of Burkholderia cepacia strain SM4 and with the GDH identified in strain PMB3(1) in our study, suggesting that such enzyme may be broadly conserved in Burkholderiales.

\section{CONCLUSION}

This study elucidated the main molecular mechanism used by collimonads to weather mineral. Our results show that their effective MW ability is likely due to an enzymatic activity based on a PQQ-independent GMC-DH capable of oxidizing glucose to gluconic acid (i.e., a PQQ-independent glucose dehydrogenase). This crucial step of the direct oxidative pathway leads to a high production of protons jointly with the oxidation of glucose and an important acidification of the nearby environment and consequently the dissolution of the minerals. This enzyme appears conserved among collimonads explaining their conserved effectiveness. The variations of sequence observed in the GMC_C domain of the large subunit of this enzyme may explain why some of the related taxa (i.e., Herbaspirillum, Janthinobacterium) harbour a 
Picard et al.

lower effectiveness at weathering minerals than collimonads. Our results represent the first demonstration that MW in bacteria is not exclusively explained by the PQQ-dependent GDH production of gluconate and that an alternative pathway based on a PQQ-independent GDH also exists in MW bacteria lacking the PQQ system. As such enzyme is largely distributed in Bacteria, Archaea and in some Eukaryotes (Sützl et al. 2019), it may open new perspectives in the understanding of the MW process by microorganisms and plants. Noticeably, our genomic analyses revealed that some bacteria harbour both the PQQ-dependent and PQQindependent GDH in their genome as stated in some representative strains of the genus Burkholderia, Glaciimonas, Gluconobacter or Pantoea (this study; Uroz et al. in press). The next step for future researches will be to determine whether i) the GDH activity is regulated by the availability of inorganic nutrients $(\mathrm{P}, \mathrm{K}, \mathrm{Mg} \ldots)$ as is the case for the PQQ-dependent GDH (Sasnow et al. 2016) or the presence/absence of a mineral (Uroz et al. 2020) and ii) the GDH genes can be used as biomarkers of the presence of the mineral weathering function into the soil.

\section{ACKNOWLEDGMENTS}

This work was supported by grants from the EC2CO program and the Labex ARBRE to S.U. L.P. was also supported by a fellowship from the French Ministère de l'Enseignement Supérieur, de la Recherche et de l'Innovation. The UMR1136 and UR1138 are supported by the ANR through the Laboratory of Excellence Arbre (ANR-11-LABX-0002-01). The authors thank Dr. P. Frey-Klett for helpful discussions, E. Morin for bioinformatics support and the MICROSCOPE team (Genoscope) for the support provided on the genome of strain PMB31.

\section{REFERENCES}


Picard et al.

Alder NN, Theg SM. Energetics of protein transport across biological membranes: A study of the thylakoid delta pH-dependent/cpTat pathway. Cell Press. 2003;112:231-242.

Allen SCH, Barrett CML, Ray N, Robinson C. Essential cytoplasmic domains in the Escherichia coli TatC protein. J Biol Chem. 2002;277:10362-10366.

Altschul SF, Madden TL, Schaffer AA, Zhang J, Zhang Z, Miller W and Lipman, DJ. Gapped BLAST and PSI-BLAST: a new generation of protein database search programs. Nucleic Acids Res. 1997; 25:3389-3402.

Babu-Khan S, Yeo TC, Martin WL, et al. Cloning of a mineral phosphate-solubilizing gene from Pseudomonas cepacia. Appl Environ Microbiol 1995;61:972-978.

Balland C, Poszwa A, Leyval C, Mustin C. Dissolution rates of phyllosilicates as a function of bacterial metabolic diversity. Geochim Cosmochim Acta 2010; 74:5478-5493.

Bendtsen J, Nielsen H, Widdick D, Palmer T, Brunak S. Prediction of twin-arginine signal peptides. BMC Bioinformatics 2005; 6:167.

Bonneville S, Smits MM, Brown A, et al. Plant-driven fungal weathering: Early stages of mineral alteration at the nanometer scale. Geology. 2009; 37:615-618.

Brantley SL. Kinetics of Mineral Dissolution, p. 151-210. In Brantley, SL, Kubicki, JD, White, AF (eds.), Kinetics of Water-Rock Interaction. 2008; Springer New York, New York, NY.

Calvaruso C, Mareschal L, Turpault M-P, Leclerc E. Rapid clay weathering in the rhizosphere of norway spruce and oak in an acid forest ecosystem. Soil Sci Soc Am J. 2009; 73:331-338.

Calvaruso C, Turpault M-P, Frey-Klett P. Root-associated bacteria contribute to mineral weathering and to mineral nutrition in trees: a budgeting analysis. Appl Environ Microbiol. $2006 ; 72: 1258-1266$.

Calvaruso, C., Turpault, M. P., Leclerc, E., Ranger, J., Garbaye, J., Uroz, S., \& Frey-Klett, P. Influence of forest trees on the distribution of mineral weathering-associated bacterial 
Picard et al.

communities of the Scleroderma citrinum mycorrhizosphere. Appl Environ Microbiol. 2010;76:4780-4787.

Cavener DR. GMC oxidoreductases: A newly defined family of homologous proteins with diverse catalytic activities. $J$ Mol Biol. 1992; 223:811-814.

Chhabra S, Brazil D, Morrissey J, Burke JI, et al. Characterization of mineral phosphate solubilization traits from a barley rhizosphere soil functional metagenome. Microbiol Open $2013 ; 2: 717-724$.

Chilton M-D, Currier TC, Farrand SK, Bendich AJ, et al. Agrobacterium tumefaciens DNA and PS8 bacteriophage DNA not detected in crown gall tumors. Proc Natl Acad Sci $1974 ; 71: 3672-3676$.

Colin Y, Nicolitch O, Turpault M-P, Uroz S. Mineral types and tree species determine the functional and taxonomic structures of forest soil bacterial communities. Appl Environ Microbiol. 2017; 83:e02684-16.

Collignon, C., Uroz, S., Turpault, M. P., \& Frey-Klett, P. (2011). Seasons differently impact the structure of mineral weathering bacterial communities in beech and spruce stands. Soil Biol and Biochem. 2011;43:2012-2022.

Crow A, Le Brun NE, Oubrie A. The role of ResA in type II cytochrome c maturation. Biochem Soc Trans. 2005; 33:149-151.

Dennis JJ, Zylstra GJ. Plasposons: modular self-cloning minitransposon derivatives for rapid genetic analysis of Gram-negative bacterial genomes. Appl Environ Microbiol. 1998; $64: 2710-2715$.

Derrien D, Marol C, Balesdent J. The dynamics of neutral sugars in the rhizosphere of wheat. An approach by 13 C pulse-labelling and GC/C/IRMS. Plant and Soil. 2004; 267: 243-253. 
Picard et al.

DeShazer D, Brett PJ, Carlyon R, Woods DE. Mutagenesis of Burkholderia pseudomallei with Tn5-OT182: isolation of motility mutants and molecular characterization of the flagellin structural gene. J Bacteriol. 1997; 179:2116-2125.

Dilks K, Rose RW, Hartmann E, Pohlschroder M. Prokaryotic utilization of the TwinArginine Translocation pathway: a genomic survey. J Bacteriol. 2003; 185:1478-1483.

Driessen AJ, Wickner W. Proton transfer is rate-limiting for translocation of precursor proteins by the Escherichia coli translocase. Proc Natl Acad Sci. 1991; 88:2471-2475.

Ebert BE, Kurth F, Grund M, Blank LM, et al. Response of Pseudomonas putida KT2440 to increased NADH and ATP demand. Appl Environ Microbiol. 2011; 77:6597-6605.

El-Gebali S, Mistry J, Bateman A, Eddy SR, et al. The Pfam protein families database in Nucleic Acids Res. 2019; 47:D427-D432.

Ferri S, Kojima K, Sode K. Review of glucose oxidases and glucose dehydrogenases: A bird's eye view of glucose sensing enzymes. J Diabetes Sci Technol. 2011;5:1068-1076.

Gadd GM. Geomycology: biogeochemical transformations of rocks, minerals, metals and radionuclides by fungi, bioweathering and bioremediation. Mycol Res. 2007; 111:3-49.

Goldstein AH. Recent progress in understanding the molecular genetics and biochemistry of calcium phosphate solubilization by Gram negative bacteria. Biol Agric Hortic. 1995;12:185193.

Goldstein A, Lester T, Brown J. Research on the metabolic engineering of the direct oxidation pathway for extraction of phosphate from ore has generated preliminary evidence for PQQ biosynthesis in Escherichia coli as well as a possible role for the highly conserved region of quinoprotein dehydrogenases. Biochim Biophys Acta BBA - Proteins Proteomics. 2003; $1647: 266-271$. 
Picard et al.

Gouy M, Guindon S, Gascuel O. SeaView Version 4: A Multiplatform Graphical User Interface for Sequence Alignment and Phylogenetic Tree Building. Mol Biol Evol. 2010; $27: 221-224$.

Grayston SJ, Campbell CD. Functional biodiversity of microbial communities in the rhizospheres of hybrid larch (Larix eurolepis) and Sitka spruce (Picea sitchensis). Tree Physiol. 1996;16:1031-1038.

Hinsinger P, Plassard C, Tang C, Jaillard B. Origins of root-mediated $\mathrm{pH}$ changes in the rhizosphere and their responses to environmental constraints: A review. Plant Soil 2003; 248:43-59.

Jolivet C, Angers DA, Chantigny MH, Andreux F, Arrouays D. Carbohydrate dynamics in particle-size fractions of sandy spodosols following forest conversion to maize cropping. Soil Biology and Biochemistry. 2006; 38:2834-2842.

Jongmans AG, van Breemen N, Lundström U, van Hees PAW, et al. Rock-eating fungi. Nature 1997; 389:682-683.

Kawai S, Goda-Tsutsumi M, Yakushi T, Kano K, et al. Heterologous overexpression and characterization of a flavoprotein-cytochrome c complex fructose dehydrogenase of Gluconobacter japonicus NBRC3260. Appl Environ Microbiol. 2013; 79:1654-1660.

Kovacs N. Identification of Pseudomonas pyocyanea by the oxidase reaction. Nature 1956; 178:703-703.

Kovach ME, Elzer PH, Steven Hill D, Robertson GT, et al. Four new derivatives of the broad-host-range cloning vector pBBR1MCS, carrying different antibiotic-resistance cassettes. Gene 1995; 166:175-176.

Koele N, Turpault M-P, Hildebrand EE, Uroz S, et al. Interactions between mycorrhizal fungi and mycorrhizosphere bacteria during mineral weathering: Budget analysis and bacterial quantification. Soil Biol Biochem. 2009; 41:1935-1942. 
Picard et al.

Kranz RG, Richard-Fogal C, Taylor J-S, Frawley ER. Cytochrome c biogenesis: mechanisms for covalent modifications and trafficking of heme and for heme-iron redox control. Microbiol Mol Biol Rev. 2009; 73:510-528.

Landeweert R, Hoffland E, Finlay RD, Kuyper TW, et al. Linking plants to rocks: ectomycorrhizal fungi mobilize nutrients from minerals. Trends Ecol Evol. 2001; 16:248-254. Lepleux C, Turpault MP, Oger P, Frey-Klett P, Uroz S. 2012. Correlation of the abundance of betaproteobacteria on mineral surfaces with mineral weathering in forest soils. Appl Environ Microbiol. 2012; 78:7114-7119.

Leveau JHJ, Uroz S, de Boer W. The bacterial genus Collimonas : mycophagy, weathering and other adaptive solutions to life in oligotrophic soil environments. Environ Microbiol. $2010 ; 12: 281-292$.

Lidbury IDEA, Murphy ARJ, Scanlan DJ, Bending GD, et al. Comparative genomic, proteomic and exoproteomic analyses of three Pseudomonas strains reveals novel insights into the phosphorus scavenging capabilities of soil bacteria: Comparative genomic, proteomic and exoproteomic analyses of three Pseudomonas strains. Environ Microbiol. 2016;18:35353549.

Liu ST, Lee LY, Tai CY, Hung CH, et al. Cloning of an Erwinia herbicola gene necessary for gluconic acid production and enhanced mineral phosphate solubilization in Escherichia coli HB101: nucleotide sequence and probable involvement in biosynthesis of the coenzyme pyrroloquinoline quinone. J Bacteriol. 1992;174:5814-5819.

Martin, F., D. Canet, Marchal JP. In vivo abundance 13C NMR studies of the carbohydrate storage in ectomycorrhizal fungi. Physiol Veg. 1984; 22:733-743.

Matsushita, K., Ameyama, M. [24] d-Glucose dehydrogenase from Pseudomonas fluorescens, membrane-bound. In Methods in enzymology (Vol. 89, pp. 149-154). 1982; Academic Press. 
Picard et al.

Medeiros PM, Fernandes MF, Dick RP, Simoneit BR. Seasonal variations in sugar contents and microbial community in a ryegrass soil. Chemosphere. 2006; 65:832-839.

Mela F, Fritsche K, de Boer W, van den Berg $\mathrm{M}$ et al. Comparative genomics of bacteria from the genus Collimonas: linking (dis)similarities in gene content to phenotypic variation and conservation. Environ Microbiol Rep. 2012; 4:424-432.

Palmer T, Berks BC. The twin-arginine translocation (Tat) protein export pathway. Nat Rev Microbiol. 2012 10:483-496.

Picard L, Oger, P, Turpault, M-P, Uroz, S. Draft genome of Collimonas pratensis strain PMB3(1), an effective mineral weathering and chitin hydrolyzing bacterial strain. Microbial Genom. Res. DOI: 10.1128/MRA.00601-20

Pospiech AA versatile quick-prep of genomic DNA from Gram-positive bacteria. Trends Genet . 199511:217-218.

Puente ME, Bashan Y, Li CY, Lebsky VK. Microbial populations and activities in the rhizoplane of rock-weathering desert plants. II. Growth promotion of cactus seedlings. Plant Biol. 2004; 6:643-649.

Ranger J, Turpault M-P. Input-output nutrient budgets as a diagnostic tool for sustainable forest management. For Ecol Manag. 1999; 122:139-154.

Rodríguez H, Fraga R. Phosphate solubilizing bacteria and their role in plant growth promotion. Biotechnol Adv . 1999; 17:319-339.

Saichana I, Moonmangmee D, Adachi O, Matsushita K, et al. Screening of thermotolerant Gluconobacter strains for production of 5-Keto-D-gluconic acid and disruption of Flavin Adenine Dinucleotide-containing D-gluconate dehydrogenase. Appl Environ Microbiol. 2009; $75: 4240-4247$.

Sasnow SS, Wei H, Aristilde L. Bypasses in intracellular glucose metabolism in iron-limited Pseudomonas putida. MicrobiologyOpen 2016; 5:3-20. 
Picard et al.

Shiota M, Yamazaki T, Yoshimatsu K, Kojima K, et al. An Fe-S cluster in the conserved Cys-rich region in the catalytic subunit of FAD-dependent dehydrogenase complexes. Bioelectrochem. 2016; 112:178-183.

Sützl L, Foley G, Gillam EMJ, Bodén M, et al. The GMC superfamily of oxidoreductases revisited: analysis and evolution of fungal GMC oxidoreductases. Biotechnol Biofuels 2019; $12: 1-18$.

Toyama H, Furuya N, Saichana I, Ano Y, et al. Membrane-bound, 2-keto-D-gluconateyielding D-gluconate dehydrogenase from Gluconobacter dioxyacetonicus IFO 3271: molecular properties and gene disruption. Appl Environ Microbiol. 2007; 73:6551-6556.

Toyama H, Soemphol W, Moonmangmee D, Adachi O, et al. Molecular properties of membrane-bound FAD-containing D-Sorbitol dehydrogenase from thermotolerant Gluconobacter frateurii isolated from Thailand. Biosci Biotechnol Biochem. 2005; 69:11201129.

Turpault MP, Nys C, Calvaruso C. Rhizosphere impact on the dissolution of test minerals in a forest ecosystem. Geoderma. 2009; 153:147-154.

Udovičić M, Sievers M, Zhang D-C, Margesin R, et al. Glaciimonas alpina sp. nov. isolated from alpine glaciers and reclassification of Glaciimonas immobilis $\mathrm{Cr} 9-12$ as the type strain of Glaciimonas alpina sp. nov. Int J Syst Evol Microbiol. 2015; 65:1779-1785.

Uroz S, Calvaruso C, Turpault MP, Pierrat JC, et al. Effect of the mycorrhizosphere on the genotypic and metabolic diversity of the bacterial communities involved in mineral weathering in a forest soil. Appl Environ Microbiol. 2007;73:3019-3027.

Uroz S, Calvaruso C, Turpault M-P, Frey-Klett P. Mineral weathering by bacteria: ecology, actors and mechanisms. Trends Microbiol. 2009; 17:378-387. 
Picard et al.

Uroz S, Calvaruso C, Turpault M-P, Sarniguet A, et al. 2009b. Efficient mineral weathering is a distinctive functional trait of the bacterial genus Collimonas. Soil Biol Biochem. 2009; $41: 2178-2186$.

Uroz S, Turpault M-P, Van Scholl L, Palin B, et al. Long term impact of mineral amendment on the distribution of the mineral weathering associated bacterial communities from the beech Scleroderma citrinum ectomycorrhizosphere. Soil Biol Biochem. 2011; 43:2275-2282.

Uroz S, Picard L, Turpault M-P, Auer L, et al. Dual transcriptomic and proteomic analyses of the early stage of interaction between Caballeronia mineralivorans PML1(12) and mineral. In press. Environmental Microbiol. doi:10.1111/1462-2920.15159

Vallenet D, Engelen S, Mornico D, Cruveiller S, MicroScope: a platform for microbial genome annotation and comparative genomics. Database 2009.

Wagh J, Shah S, Bhandari P, Archana G,et al. Heterologous expression of pyrroloquinoline quinone (pqq) gene cluster confers mineral phosphate solubilization ability to Herbaspirillum seropedicae Z67. Appl Microbiol Biotechnol. 2014; 98:5117-5129.

Wang Y-L, Sun L-J, Xian C-M, Kou F-L, et al. Interactions between biotite and the mineralweathering bacterium Pseudomonas azotoformans F77. Appl Environ Microbiol. 2020 86:e02568-19.

Yamaoka H, Yamashita Y, Ferri S, Sode K. Site directed mutagenesis studies of FADdependent glucose dehydrogenase catalytic subunit of Burkholderia cepacia. Biotechnol Lett. $2008 ; 30: 1967-1972$.

Zámocký M, Hallberg M, Ludwig R, Divne C, et al. Ancestral gene fusion in cellobiose dehydrogenases reflects a specific evolution of GMC oxidoreductases in Fungi. Gene 2004; $338: 1-14$ 
Picard et al.

928

929

930

931

932

933

934

935

936

937

938

939

940

941

942

943

944

945

946

947

948

949

950

951

952

953

954

955

956 957

Zhang, Z., Huang, J., He, L., Sheng, X. Distinct weathering ability and populations of culturable mineral-weathering bacteria in the rhizosphere and bulk soils of Morus alba. Geomicrobiology J. 2016; 33:39-45.

(1)

2

(1)

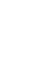

36

7

9

40

1

42

43

4

46

47

48

49

50

51

\section{2}

3 
Figure 1: Thin layer chromatography analysis of gluconic acid production by the wild

\section{type strain PMB3(1) of Collimonas pratensis}

A volume of $8 \mu \mathrm{l}$ of supernatant of ABm culture was spotted on the TLC. Cultures were done in $\mathrm{ABm}$ medium supplemented with $10 \mathrm{~g} / 1$ of glucose inoculated or not with the WT strain PMB3(1). The supernatant was recovered after 4 days of incubation at $25^{\circ} \mathrm{C}$. A volume of 4 $\mu 1$ of standards was spotted on the TLC. Standards correspond to $100 \mathrm{mM}$ solutions of glucose, gluconate, 2KGA and 5KGA. After revelation, glucose appeared in dark blue spots, gluconate in pink, 2KGA in brown and 5KGA in dark purple spot. The pink arrow indicates the pink spot of the gluconate standard.

\section{Figure 2: Biotite dissolution assay by the WT and mutant strains}

(A) Measure of iron released from biotite after 7 days of incubation at $25^{\circ} \mathrm{C}$ in $\mathrm{BHm}$ supplemented with (2 g/l) glucose ; (B) Measure of $\mathrm{pH}$ measurement with bromocresol green. The control treatment termed 'Biotite' corresponds to the non-inoculated treatment. It allows the measurement of the spontaneous release of iron from biotite in the medium in our experimental conditions. The second control termed 'medium' corresponds to the noninoculated medium without biotite. Each value is the mean of three independent replicates \pm the standard error of the mean. Measures with different letters are significantly different according to an ANOVA test $(\mathrm{P}<0.05)$; (C) Individual mineral-weathering potentials $(\mathrm{pH}$ versus Fe released) of the WT strain and related MW mutants. White and grey squares correspond to the controls of the experiment (white, medium without biotite and non inoculated; grey, medium with biotite and non inoculated). The two curves indicate the 
Picard et al.

982

983

984

985

986

987

988

989

990

991

992

993

994

995

996

997

998

999

1000

1001

1002

1003

1004

1005

1006

mineral-weathering effect of a complexing agent (citric acid) (dashed line) and a strong acid (hydrochloric acid) (solid line).

\section{Figure 3: Genomic region of the plasposon insertion in the different mutants}

For each mutant, the genes have been represented with large horizontal arrows and their length was scaled according to their nucleotidic size. The genes or group of genes directly impacted by the Tn5-OT182 insertion are filled with colour. The small black arrow indicates the location of the insertion of the Tn5-OT182 in the genome of PMB3(1) as identified by BlastN for the mutants 25(10F) (A), 31(11B) (B), 34(11H) (C) and 59(7B) (D). Gene annotation is presented under each gene and the complete description is provided in Table 2 and in the supplementary Table S1, S2 and S3.

\section{Figure 4: Growth test on WT, mutants and complemented mutants in LB broth}

Growth monitoring of the wild type strain and of the mutants $25(10 \mathrm{~F}), 31(11 \mathrm{~B})$ and $34(11 \mathrm{H})$ complemented or not was done in LB medium over a period of $120 \mathrm{~h}$. Growth was performed under orbital shaking and the measures correspond to absorbance measurement at $\lambda 600 \mathrm{~nm}$. Each point is the mean of 3 independent replicates. For legibility reason, the standard error was not presented.

\section{Figure 5: Acidification ability and growth on different carbon sources for the WT and} mutants strains

The acidification (right axis) after 5 days of incubation at $25^{\circ} \mathrm{C}$ of the $\mathrm{BHm}$ medium with different carbon source (glucose, gluconate, 2keto gluconate and 5-keto gluconate) is presented by coloured circles according to the strain considered. The absorbance at $595 \mathrm{~nm}$ (left axis) representing the growth of the different strains is presented by coloured bars. The 
Picard et al.

1007

1008

1009

1010

1011

1012

1013

1014

1015

1016

1017

1018

1019

1020

1021

1022

1023

1024

1025

1026

non-inoculated medium was used as control. Each value is the mean of three independent replicates \pm the standard error of the mean.

\section{Figure 6: Molecular mechanisms of PQQ-independent GDH in mineral weathering} process of Collimonas pratensis PMB3(1)

The hypothetical functional model presented in here was generated based on the data extracted in this study and from the literature. The GDH of the strain Collimonas pratensis PMB3(1) is composed of three subunits GdhS, GdhL and GdhC (blue). The GdhL subunit is able to bind the cofactor FAD (yellow) in the cytoplasm. The complex GdhS-GdhL is formed in the cytoplasm and then transported in the periplasm. This transfer is done through the Twin Arginine Translocation system (green), due to the presence of a TAT signal of the GdhS subunit. The functioning of the TAT system is based on the proton motive force. The cytochrome subunit (GdhC) is maturated by the ResABC system (orange) and translocated in the periplasm where it fixes heme. The GDH converts glucose in gluconate (GA) and protons (pink). Gluconate is then converted to 2-Keto-gluconate (2KGA) by the gluconate dehydrogenase (grey). The conversion of glucose to gluconic acid and then to 2KGA corresponds to the direct oxidative pathway (dotted red box). The $2 \mathrm{KGA}$ can go to the cytoplasm where it is then converted into 6-P-gluconate by a 2-keto gluconate kinase and a 2keto gluconate 6-phosphate reductase prior to enter in the Pentose or the Entner-Doudoroff pathways. Both GA and 2KGA support the growth of strain PMB3(1). Protons produced by GDH activity lead to an acidification of the extracellular environment and permit the dissolution of minerals through acidolysis. The mineral weathering makes nutrients available to bacteria. 

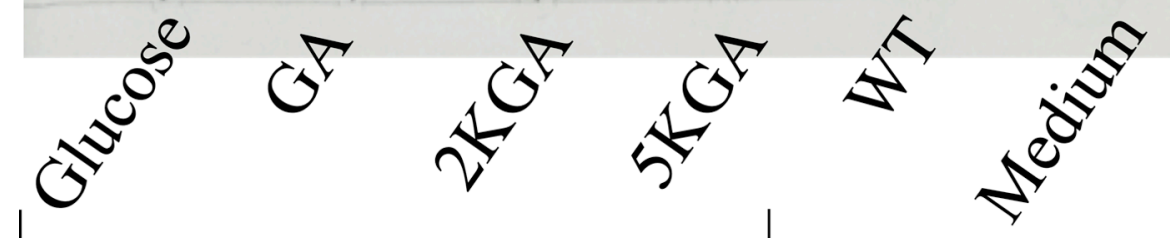

Standard (100mM)

1036

1037

1038

1039

1040

1041 
Picard et al.

1043

1044

1045

1046

1047

1048

1049

A
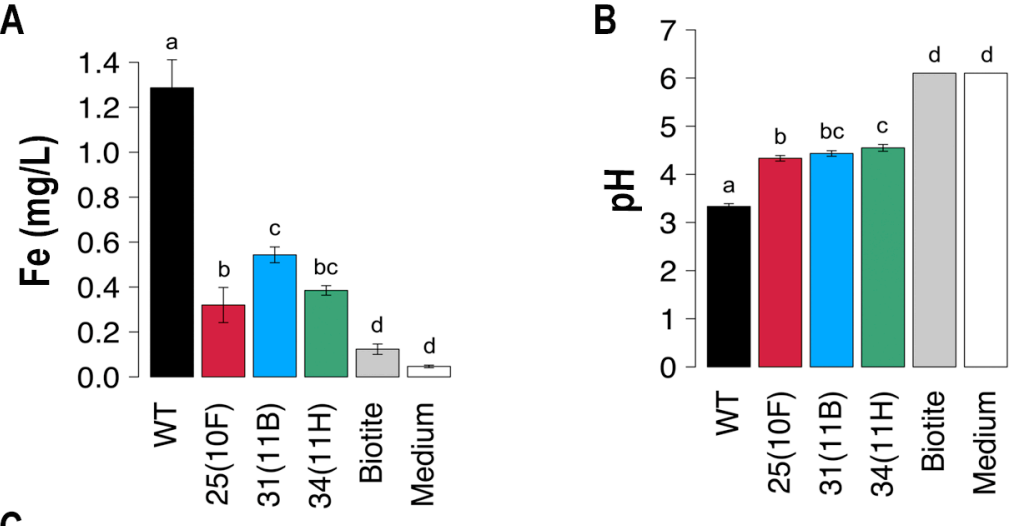

C
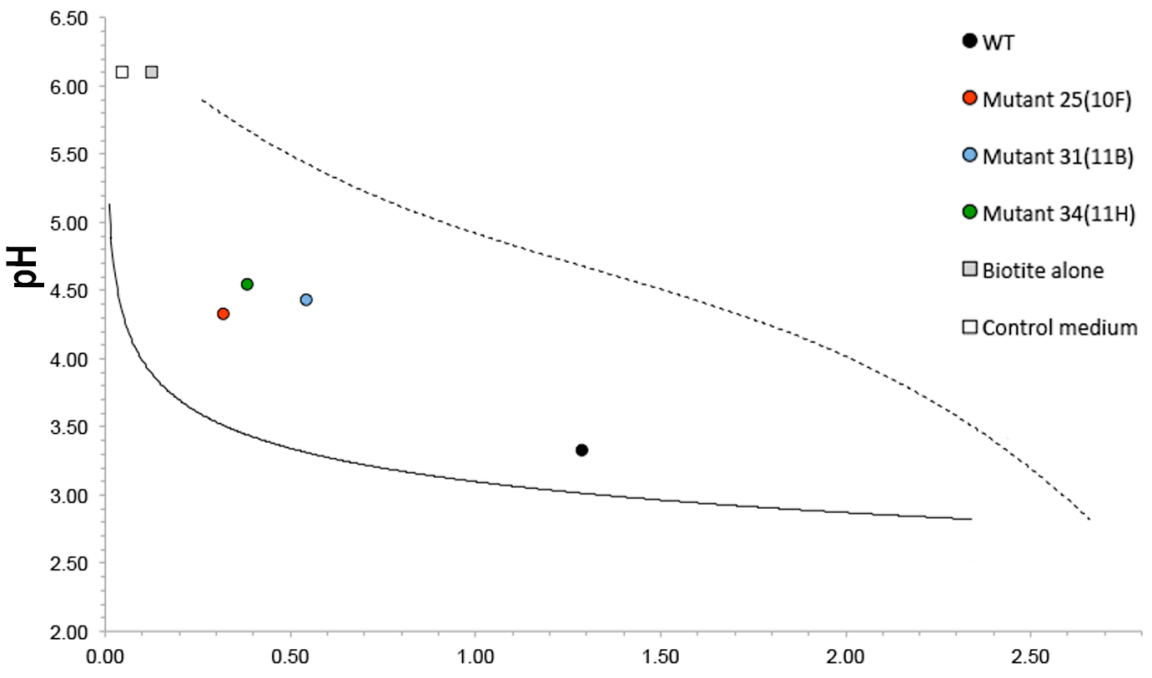

1050

$\mathrm{Fe}(\mathrm{mg} / \mathrm{L})$

1051

1052

1053

1054

1055

1056 
Picard et al.

1057

1058

1059

1060

1061

1062

A Mutant 25(10F)

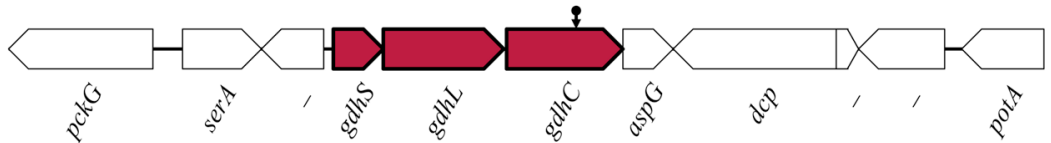

B Mutant 31(11B)

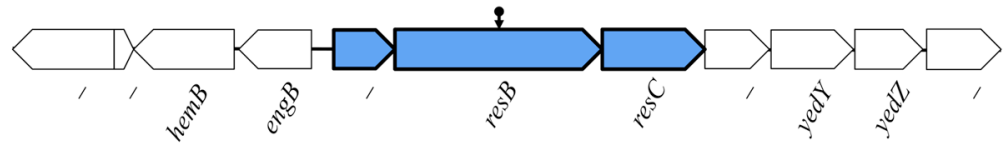

C Mutant 34(11H)

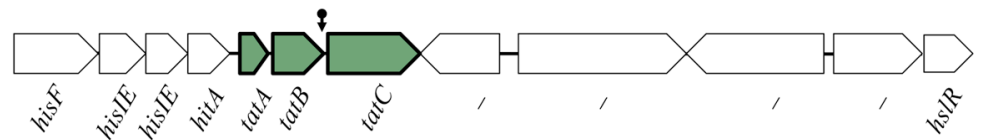

D Mutant 59(7B)

1063

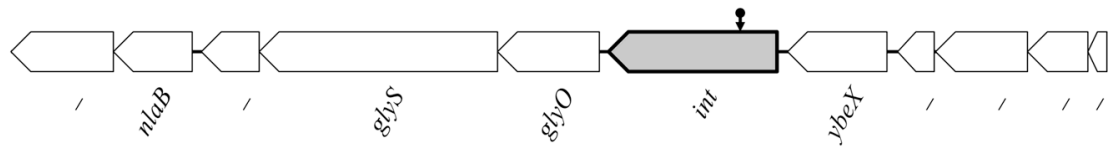

1064

1065

1066

1067

1068

1069

1070

1071

1072

1073

1074

1075

1076 
Picard et al.

1077

1078

1079

1080

1081

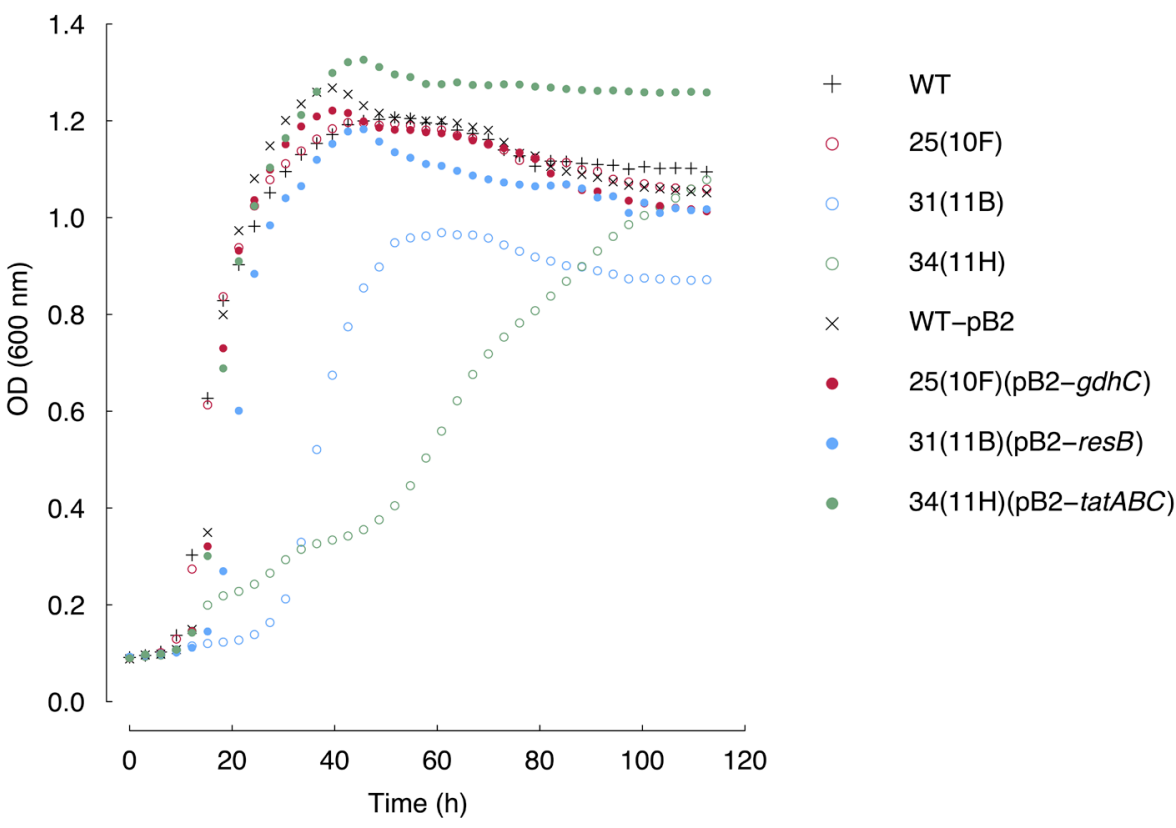

1082

1083

1084

1085

1086

1087

1088

1089

1090

1091

1092

1093

1094

1095 
Picard et al.

1096

1097

1098

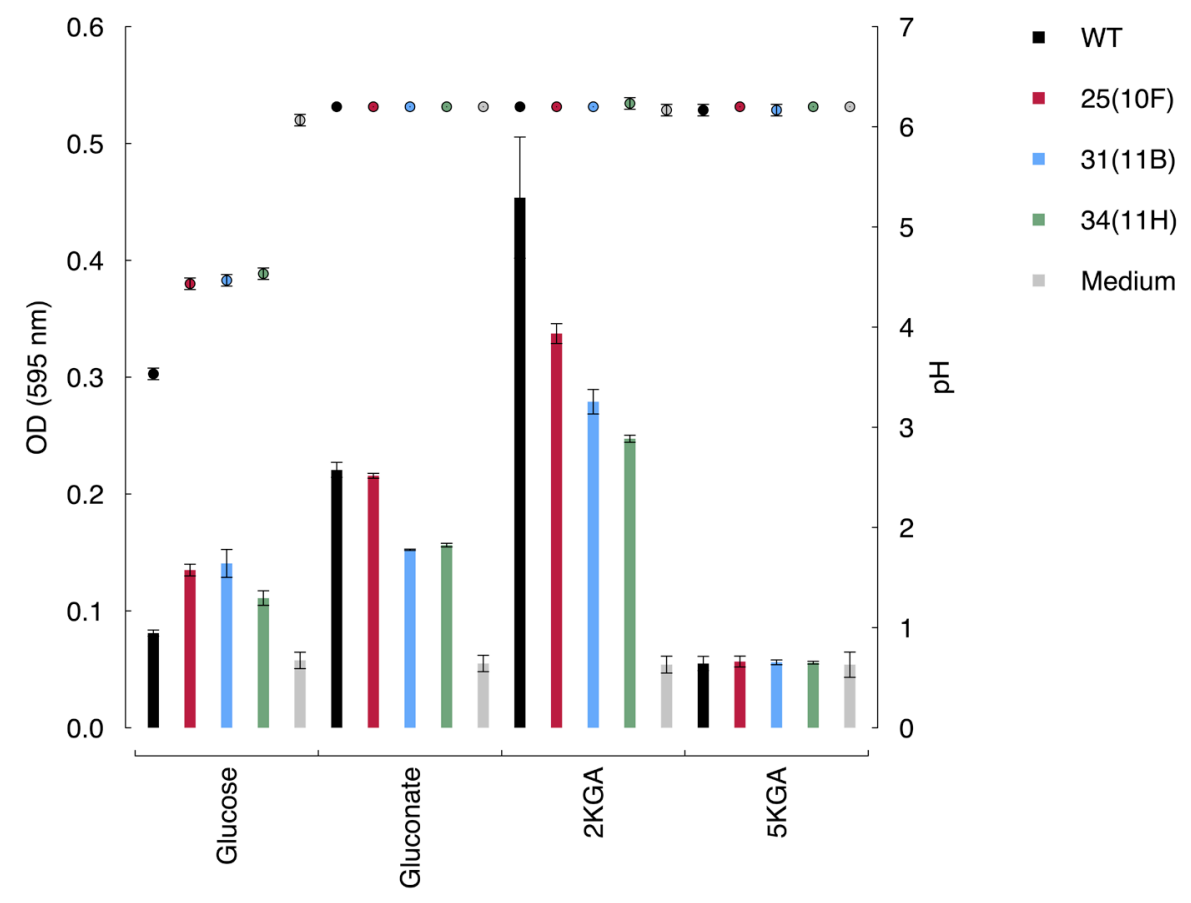

1099

1100

1101

1102

1103

1104

1105

1106

1107

1108

1109

1110

1111

1112

1113

1114 


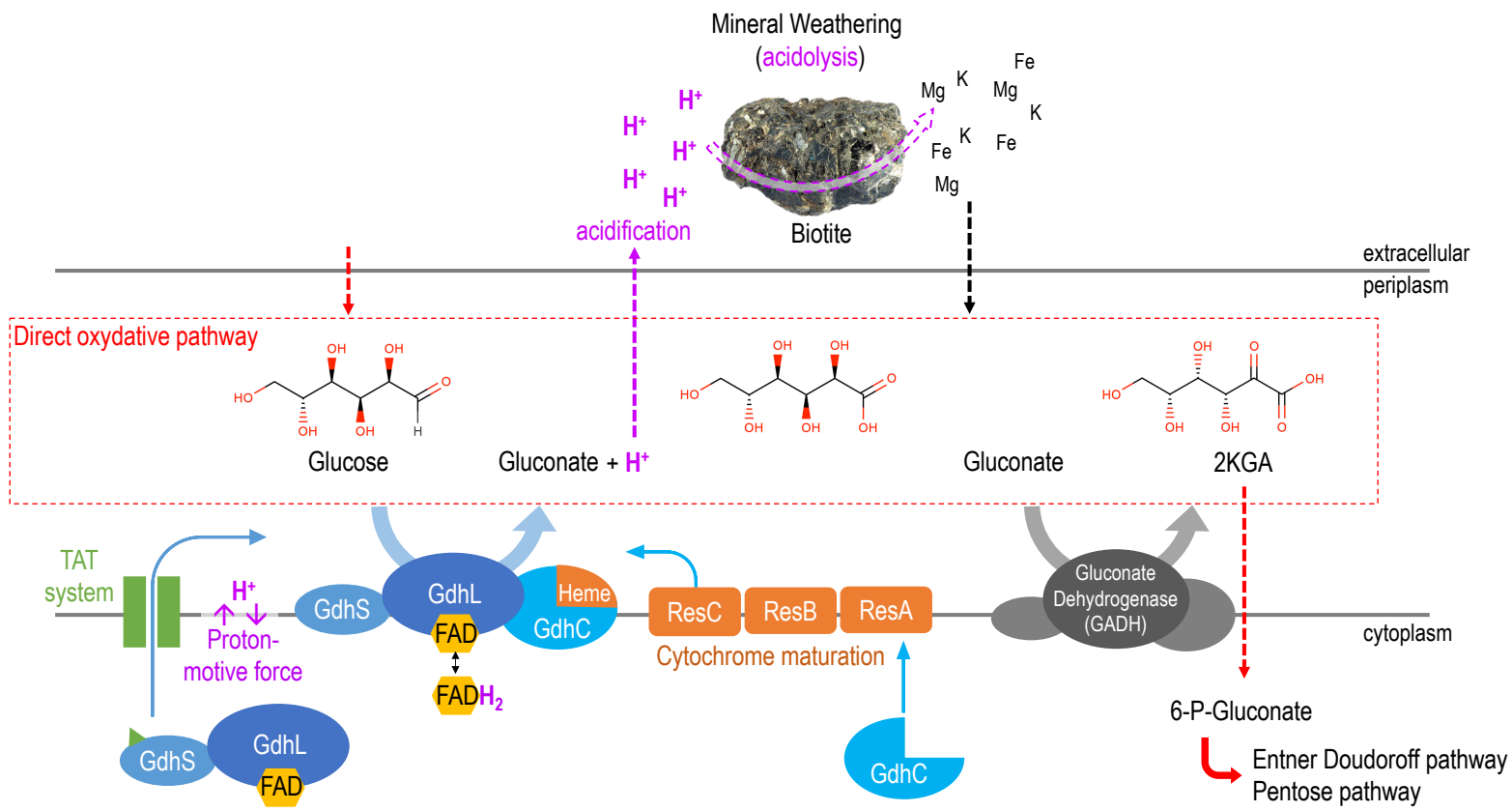

1129 Identification of a novel type of glucose dehydrogenase involved in the mineral weathering ability of Collimonas pratensis strain PMB3(1)

1131

1132 Picard, L. ${ }^{1,2}$, Turpault, M-P. ${ }^{2}$, Oger, P.M. ${ }^{3}$, Uroz, S. ${ }^{1,2 \#}$ 
Picard et al.

1133

1134 
Picard et al.

1135 Table S1 : Description of the genomic region of the plasposon insertion in mutant 31(11B)

\begin{tabular}{|c|c|c|c|c|c|c|}
\hline $\begin{array}{l}\text { Accession } \\
\text { number }\end{array}$ & Putative function & $\begin{array}{c}\text { Gene } \\
\text { annotation }\end{array}$ & $\begin{array}{l}\text { Length } \\
\text { (nt) }\end{array}$ & & $\begin{array}{c}\text { BLASTP } \\
(\% \text { Id against NCBI) }\end{array}$ & \\
\hline NKI71669.1 & $\begin{array}{c}\mathrm{Mg} 2+\text { transporter protein, cora- } \\
\text { like protein }\end{array}$ & - & 1149 & $93 \%$ & $\begin{array}{c}\text { Magnesium transporter cora family } \\
\text { protein [WP_098495086.1] }\end{array}$ & Collimonas sp. PA-H2 \\
\hline NI* & Protein of unknown function & - & 195 & $97 \%$ & $\begin{array}{c}\text { Hypothetical protein cpter291_0433 } \\
\text { [AMP12718.1] }\end{array}$ & Collimonas pratensis \\
\hline NKI71670.1 & $\begin{array}{l}\text { Delta-aminolevulinic acid } \\
\text { dehydratase }\end{array}$ & hemB & 1068 & $99 \%$ & Porphobilinogen synthase [PFH10198.1] & Collimonas sp. PA-H2 \\
\hline NKI71671.1 & $\begin{array}{l}\text { Putative GTP-binding protein } \\
\text { engb }\end{array}$ & engB & 732 & $95 \%$ & $\begin{array}{l}\text { Yiha family ribosome biogenesis GTP- } \\
\text { binding protein [WP_098495089.1] }\end{array}$ & Collimonas sp. PA-H2 \\
\hline NKI71672.1 & Cytochrome c4 & - & 666 & $99 \%$ & Cytochrome c4 [WP_098495090.1] & Collimonas sp. PA-H2 \\
\hline NKI71673.1 & $\begin{array}{c}\text { Cytochrome c-type biogenesis } \\
\text { protein Ces1/ResB }\end{array}$ & resB & 2160 & $94 \%$ & $\begin{array}{c}\text { Cytochrome c biogenesis protein resb } \\
\text { [WP_098495091.1] }\end{array}$ & $\begin{array}{l}\text { Collimonas sp. PA- } \\
\text { H2 }\end{array}$ \\
\hline NKI71674.1 & $\begin{array}{l}\text { Cytochrome c-type biogenesis } \\
\text { protein ccsa/resc }\end{array}$ & resC & 1146 & $99 \%$ & $\begin{array}{l}\text { C-type cytochrome biogenesis protein } \\
\text { ccsb [WP_098497480.1] }\end{array}$ & Collimonas sp. PA-H2 \\
\hline
\end{tabular}


Picard et al.

\begin{tabular}{|c|c|c|c|c|c|c|}
\hline NKI71675.1 & Putative phosphatase yieh & - & 684 & $92 \%$ & $\begin{array}{l}\text { HAD family hydrolase } \\
\text { [WP_098495092.1] }\end{array}$ & Collimonas sp. PA-H2 \\
\hline NKI71676.1 & $\begin{array}{l}\text { Exported heme-molybdoenzyme } \\
\text { molybdopterin-containing } \\
\text { subunit yedy; TAT export }\end{array}$ & yedY & 981 & $94 \%$ & $\begin{array}{l}\text { Protein-methionine-sulfoxide reductase } \\
\text { catalytic subunit msrp [WP_098495093.1] }\end{array}$ & Collimonas sp. PA-H2 \\
\hline NKI71677.1 & $\begin{array}{l}\text { Sulfoxide reductase heme- } \\
\text { binding subunit yedz }\end{array}$ & yedZ & 669 & $89 \%$ & $\begin{array}{l}\text { Sulfoxide reductase heme-binding subunit } \\
\text { yedz [WP_098495094.1] }\end{array}$ & Collimonas sp. PA-H2 \\
\hline NKI71678.1 & $\begin{array}{l}\text { Conserved exported protein of } \\
\text { unknown function }\end{array}$ & - & 825 & $87 \%$ & Transporter [WP_092414082.1] & $\begin{array}{l}\text { Collimonas sp. } \\
\text { OK307 }\end{array}$ \\
\hline
\end{tabular}

$1136 *$ Some of the proteins listed have not been identified (NI) according to the prediction tools used by NCBI, but were predicted in the MICROSCOPE platform. 
Picard et al.

1138

1139 Table S2 : Description of the genomic region of the plasposon insertion in mutant 34(11H)

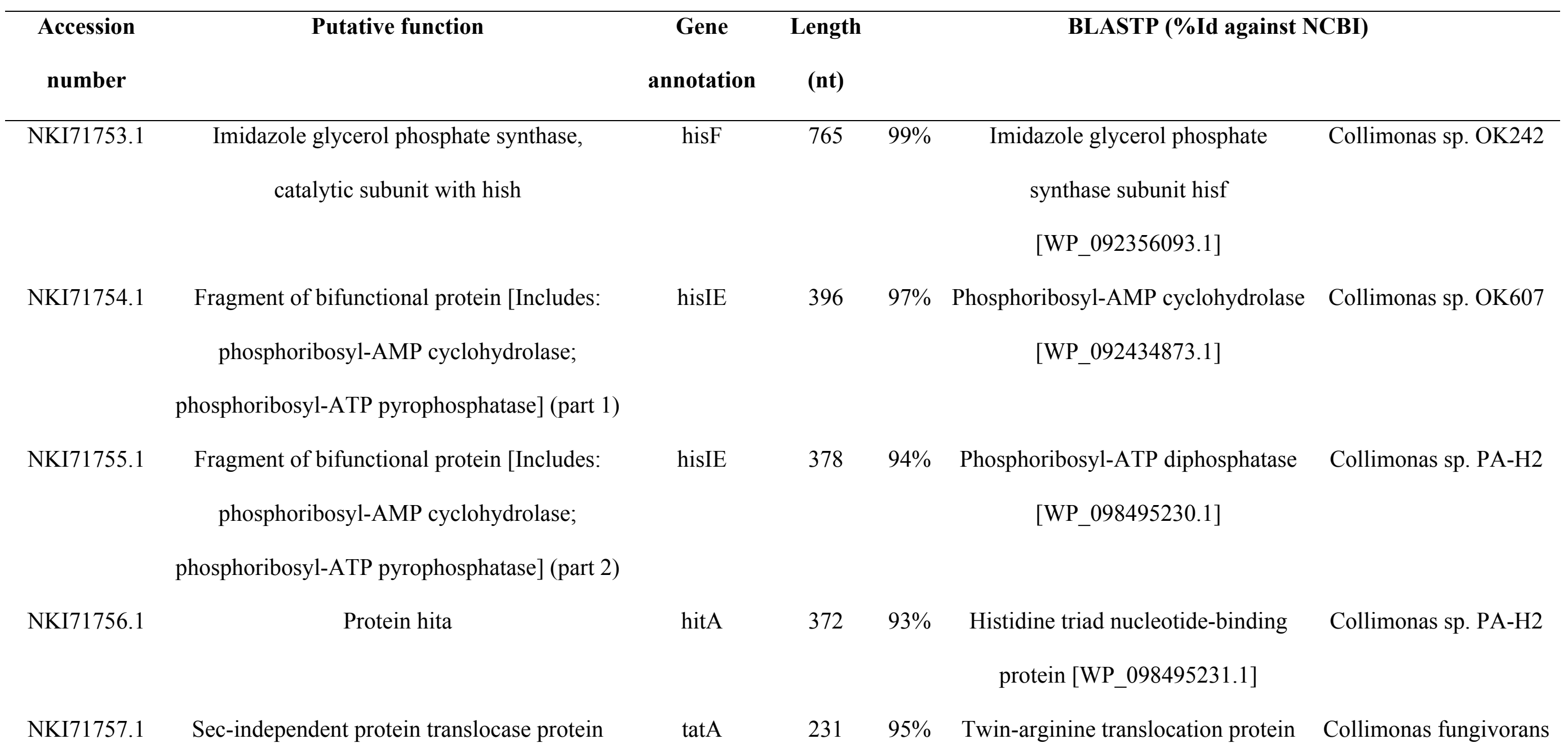


tata

NKI71758.1 Sec-independent protein translocase protein

tatb

NKI71759.1 Tatabce protein translocation system subunit

NKI71760.1 Conserved protein of unknown function

NKI71761.1 Emrb/qaca subfamily drug resistance

transporter

NKI71762.1 Putative htra-like serine protease

NKI71763.1 Putative GTP cyclohydrolase 1 type 2

NKI71764.1
Heat shock protein 15 homolog tata [AEK60361.1]

tatB

495

$93 \%$

Sec-independent protein translocase

subunit tatb [WP_098495232.1]

tatC

768

95\% Twin-arginine translocase subunit tatc [WP_098495233.1]

$-$

690

$97 \%$

DUF2461 domain-containing protein

Collimonas sp. PA-H2

$$
\text { [WP_098495234.1] }
$$

$-$

1452

$94 \%$

DHA2 family efflux MFS transporter

permease subunit [WP_098495235.1]

$-$

$1167 \quad 98 \%$

Do family serine endopeptidase

[WP_098495236.1]

$-$

768

$93 \%$

Dinuclear metal center ybgi/SA1388

Collimonas sp. PA-H2

family protein [PFH10368.1]

hslR

$96 \%$ 
Picard et al.

1141

1142 Table S3 : Description of the genomic region of the plasposon insertion in mutant 59(7B)

\begin{tabular}{|c|c|c|c|c|c|c|}
\hline Accession number & Putative function & & & & Blastp (\%id against ncbi) & \\
\hline NKI72634.1 & Zinc metalloprotease & - & 984 & $93 \%$ & $\begin{array}{c}\text { Hypothetical protein BCF11_1207 } \\
\text { [PFH08832.1] }\end{array}$ & Collimonas sp. PA-H2 \\
\hline NKI72635.1 & $\begin{array}{c}\text { 1-acyl-sn-glycerol-3-phosphate } \\
\text { acyltransferase }\end{array}$ & nlaB & 744 & $98 \%$ & $\begin{array}{l}\text { 1-acyl-sn-glycerol-3-phosphate } \\
\text { acyltransferase [WP_098493940.1] }\end{array}$ & Collimonas sp. PA-H2 \\
\hline NKI72636.1 & $\begin{array}{l}\text { D-glycero-beta-D-manno-heptose-1,7- } \\
\text { bisphosphate 7-phosphatase }\end{array}$ & - & 558 & $97 \%$ & $\begin{array}{l}\text { D-glycero-beta-D-manno-heptose 1,7- } \\
\text { bisphosphate 7-phosphatase } \\
\text { [WP_098493939.1] }\end{array}$ & Collimonas sp. PA-H2 \\
\hline NKI72637.1 & Glycine trna synthetase, beta subunit & glyS & 2133 & $96 \%$ & $\begin{array}{c}\text { Glycine--trna ligase subunit beta } \\
\text { [WP_098493938.1] }\end{array}$ & Collimonas sp. PA-H2 \\
\hline NKI72638.1 & Glycyl-trna synthetase, alpha chain & glyQ & 981 & $99 \%$ & $\begin{array}{c}\text { Glycine--trna ligase subunit alpha } \\
\text { [WP_098493937.1] }\end{array}$ & Collimonas sp. PA-H2 \\
\hline NKI72639.1 & Apolipoprotein N-acyltransferase & $\operatorname{lnt}$ & 1554 & $92 \%$ & Apolipoprotein N-acyltransferase & Collimonas sp. PA- \\
\hline
\end{tabular}


[WP_098493936.1]

H2

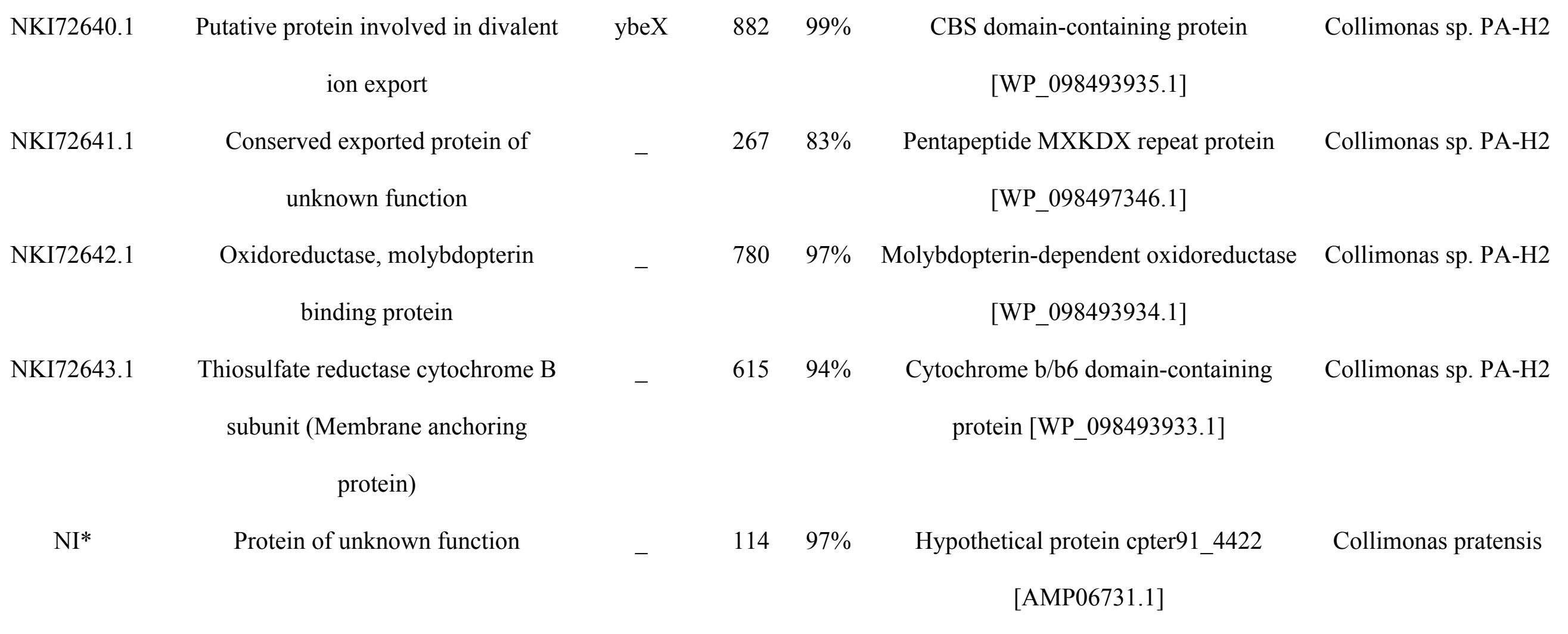

$1143 *$ Some of the proteins listed have not been identified (NI) according to the prediction tools used by NCBI, but were predicted in the MICROSCOPE platform. 


\section{Table S4: List of proteins carrying a TAT-signal in the strain Collimonas pratensis PMB3(1)}

The COG class of each protein is indicated with one-letter abbreviation as followed: P, inorganic ion transport and metabolism; Q, secondary metabolites biosynthesis, transport and catabolism; C, energy production and conversion; E, amino acid metabolism and transport; F, nucleotide metabolism and transport; G, carbohydrate metabolism and transport; $\mathrm{H}$, coenzyme and metabolism; J, translation, ribosomal structure and biogenesis; K, transcription; L, replication, recombination and repair; M, cell wall, membrane, envelope biogenesis; N, cell motility; O, posttranslational modification, protein turnover, chaperones; S, function unknown; U, intracellular trafficking, secretion, and vesicular transport; $\mathrm{W}$, extracellular structures. The bold rows indicated the proteins mentioned in the text and could be involved in MW. Some of the proteins listed have not been identified (NI) according to the prediction tools used by NCBI, but were predicted in the MICROSCOPE platform.

\begin{tabular}{|c|c|c|c|}
\hline $\begin{array}{c}\text { Accession number } \\
\text { (MAGE) }\end{array}$ & Gene annotation & Putative function & COG class \\
\hline NKI68675.1 & yagR & Aerobic-type carbon monoxide dehydrogenase, large subunit & $\mathrm{C}$ \\
\hline NKI69300.1 & iorB & Isoquinoline 1-oxidoreductase beta subunit & $\mathrm{C}$ \\
\hline NKI69617.1 & soxH & putative cytochrome $\mathrm{C}$ oxidase polypeptide II oxidoreductase protein & $\mathrm{C}$ \\
\hline NKI71676.1 & yedY & exported heme-molybdoenzyme molybdopterin-containing subunit YedY; TAT export & $\mathrm{C}$ \\
\hline NKI72252.1 & mqo & malate dehydrogenase, FAD & $\mathrm{C}$ \\
\hline NKI72324.1 & FAD & FMN-dependent dehydrogenase & $\mathrm{C}$ \\
\hline
\end{tabular}




\begin{tabular}{|c|c|c|}
\hline NKI67910.1 & & exported protein of unknown function \\
\hline NKI69616.1 & & conserved protein of unknown function \\
\hline NKI68636.1 & & putative branched-chain amino acid transport protein (ABC superfamily, peri_bind) \\
\hline NKI68806.1 & & $\mathrm{ABC}$ transporter substrate-binding protein \\
\hline NKI69719.1 & aguA & putative agmatine deiminase \\
\hline NKI69739.1 & ggtA & Gamma-glutamyltranspeptidase \\
\hline NKI72278.1 & & Monoamine oxidase \\
\hline NKI71314.1 & & conserved protein of unknown function \\
\hline NKI68557.1 & rihA & Pyrimidine-specific ribonucleoside hydrolase RihA \\
\hline NKI71053.1 & & putative nucleoside hydrolase \\
\hline NKI67981.1 & $\mathrm{ykgB}$ & putative hemagglutinin-like protein \\
\hline NKI68770.1 & bga & Beta-galactosidase \\
\hline NKI69257.1 & ytfQ & putative sugar transporter subunit: periplasmic-binding component of $A B C$ superfamily \\
\hline NKI68420.1 & & conserved membrane protein of unknown function \\
\hline NKI69773.1 & & conserved exported protein of unknown function \\
\hline NKI72549.1 & & conserved exported protein of unknown function \\
\hline NKI71161.1 & & Amidase, Asp-tRNAAsn/Glu-tRNAGln amidotransferase A subunit \\
\hline NKI71645.1 & rplP & $50 \mathrm{~S}$ ribosomal protein $\mathrm{L} 16$ \\
\hline NI & & protein of unknown function \\
\hline
\end{tabular}

C

C

E

E

E

E

E

F

G

G

G

G

G

$\mathrm{H}$

J

J 
NKI68641.1

NKI72806.1

NKI68262.1

NKI68666. 1

NKI69363.1

NKI69405.1

NKI71095.1

NKI72507.1

NKI68496.1

NKI69248.1

NKI69912.1

NKI72023.1

NKI72219.1

NKI72562.1

NKI70121.1

NKI71510.1

NKI72113.1

NKI72201.1

NKI72274.1 transposase

Non-hemolytic phospholipase C

Penicillin-binding protein $1 \mathrm{~A}$

Acid phosphatase

Non-hemolytic phospholipase C

Non-hemolytic phospholipase C

$\mathrm{N}$-acetylmuramoyl-L-alanine amidase

putative Peptide-N(4)-(N-acetyl-beta-glucosaminyl)asparagine amidase

$$
\text { peptidyl-prolyl cis-trans isomerase A (rotamase A) }
$$

Methionine sulfoxide reductase

CcsA-like protein

Lipase chaperone

Methionine-R-sulfoxide reductase

glucan biosynthesis protein, periplasmic

\section{Alkaline phosphatase}

Nitrate $\mathrm{ABC}$ transporter, nitrate-binding protein

ABC-type nitrate/sulfonate 
NKI72605.1

NKI72716.1

NKI67804.1

NKI68502.1

NI

NKI71458.1

NKI72652.1

NKI72179.1

NKI70646.1

NKI68516.1

NKI68701.1

NKI68877.1

NKI69325.1

yvnB

NKI70794.1

NKI71018.1

NKI71108.1

NKI71438.1

NKI71603.1

ophA

\section{Alkaline phosphatase}

DL-methionine transporter subunit ; periplasmic-binding component of ABC superfamily putative hydrolase

putative multicopper oxidase

protein of unknown function

conserved exported protein of unknown function

Type 4 fimbrial biogenesis protein PilY1

exported protein of unknown function

YadA-like protein

Hydrolase

putative transmembrane protein

Sulfite dehydrogenase (Cytochrome) subunit SorA apoprotein

LPXTG-motif cell wall anchor domain protein

Sorbitol/Glucose/2-Keto-D-gluconate dehydrogenase, membrane-bound, gamma subunit

Phosphoserine phosphatase

putative secreted protein

Lipoprotein

ABC peptide

conserved exported protein of unknown function
P

Q

Q

Q

Q

U

W

$\mathrm{S}$

S

S

S

S

S

S

S 
Picard et al.

NKI68510.1

NKI68544.1

NKI68550.1

NKI69712.1

NKI70227.1

NKI71034.1

NKI71518.1

NKI71778.1

NKI71790.1 conserved exported protein of unknown function

conserved protein of unknown function

protein of unknown function

conserved protein of unknown function

conserved protein of unknown function

conserved exported protein of unknown function

conserved exported protein of unknown function

exported protein of unknown function

conserved exported protein of unknown function

protein of unknown function

protein of unknown function

1157 


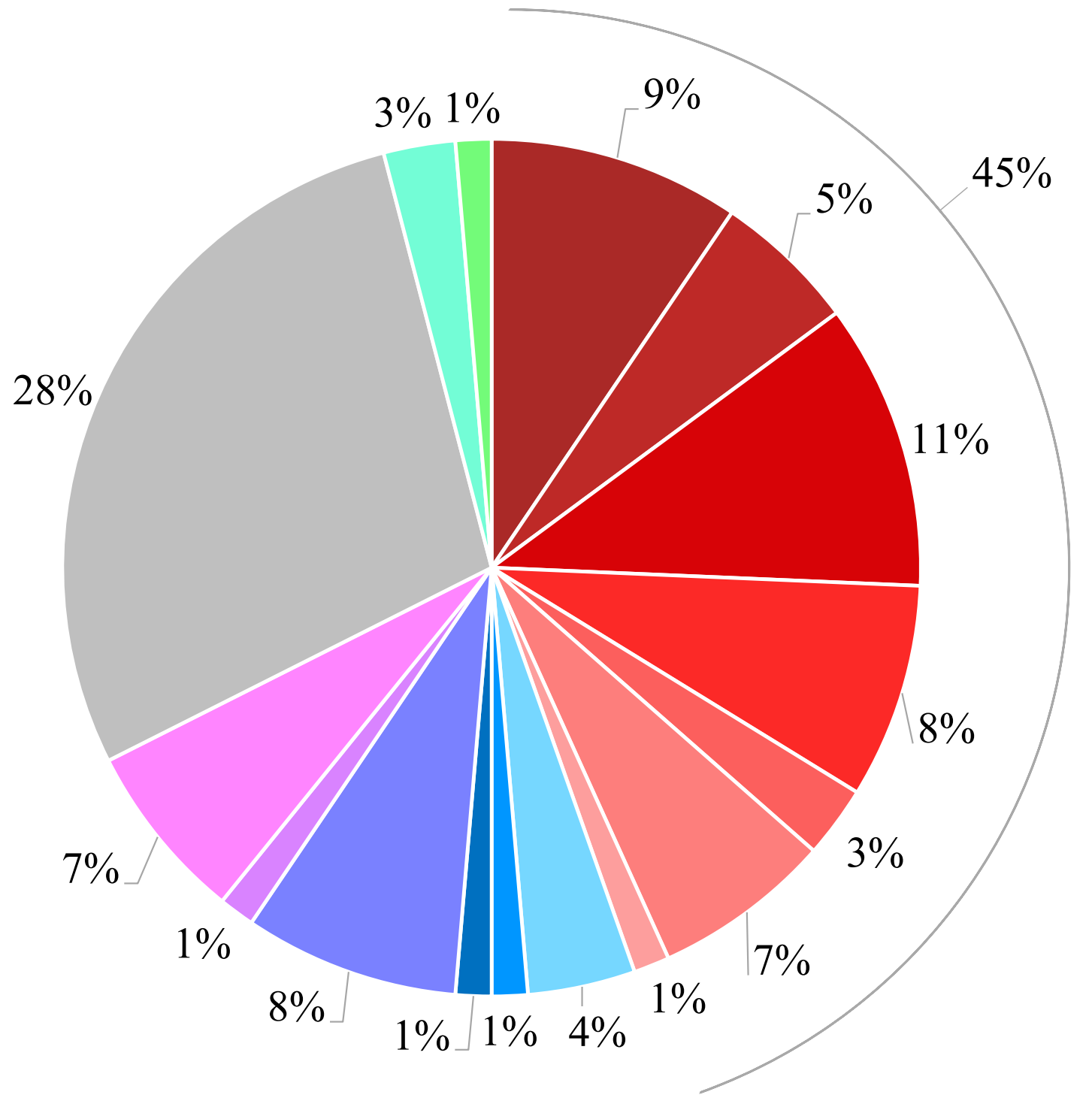

- $\mathrm{P}$

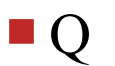

- C

- E

F

G

H

J

- $\mathrm{K}$

- L

- $\mathrm{M}$

N

O

$\mathrm{S}$

U

W

\section{Figure S1 : COG class distribution of the TAT-proteins}

1161 The proteins highlighted in red colors light to dark are those involved in metabolism, which encompass ca. $45 \%$ of the total TAT-proteins. 
1163

1164

1165

1166

1167

1168

1169

1170

1171

1172

1173

1174

1175

1176

1177

1178

1179

1180

1181

1182

1183

1184

1185

1186

1187

1188

1189

1190

1191

1192

1193

1194

1195

1196

1197

1198

1199

1200

1201

1202

1203

1204

1205

1206

1207

1208

1209

1210

1211

1212

1213
Domain 1 FAD Col_PMB31

Col.prat Ter291

Col.prat Ter91

Col.arenāe Cal35

Col sp $\mathrm{PA}-\overline{\mathrm{H}} 2$

Col.fungi_Ter6

Col.fungi Ter331

Col.arenaè_Ter282

Col.arenae Ter10

Col_sp_OK $3 \overline{0} 7$

Col sp OK 607

Col_sp_OK242

Glacii_sp_PCH181

Glacii_sp_GS1

Janthin UB̄A1134

Herba_seropedic

Herba_rubrisuba

Burkholderia

Gluc japonicus

Pantoea agglo.

Gluc_oxydans

Glucon frateuri

Glucon_fra (GADH)

domain

Col PMB31

Col.prat_Ter291

C.pratensis Ter

C.arenae Cāj35

Collimonas_sp_P

C.fungivorans $\mathrm{T}$

C.fungivorans $\mathrm{T}$

C.arenae Ter $2 \overline{8} 2$

C.arenae_Ter10

Collimonas_sp_o

Collimonas sp_o

Collimonas sp 0

Glaciimonass_sp

Glaciimonas sp

Janthin_UBA $\overline{1} 13 \overline{4}$

Herba_seropedic

Herba rubrisuba

AAN39686.1Burkh

BAM93252.1Gluco

AAF21261.1Panto AFW02570.1Gluco BAD 60913.1

Glucon frateuri
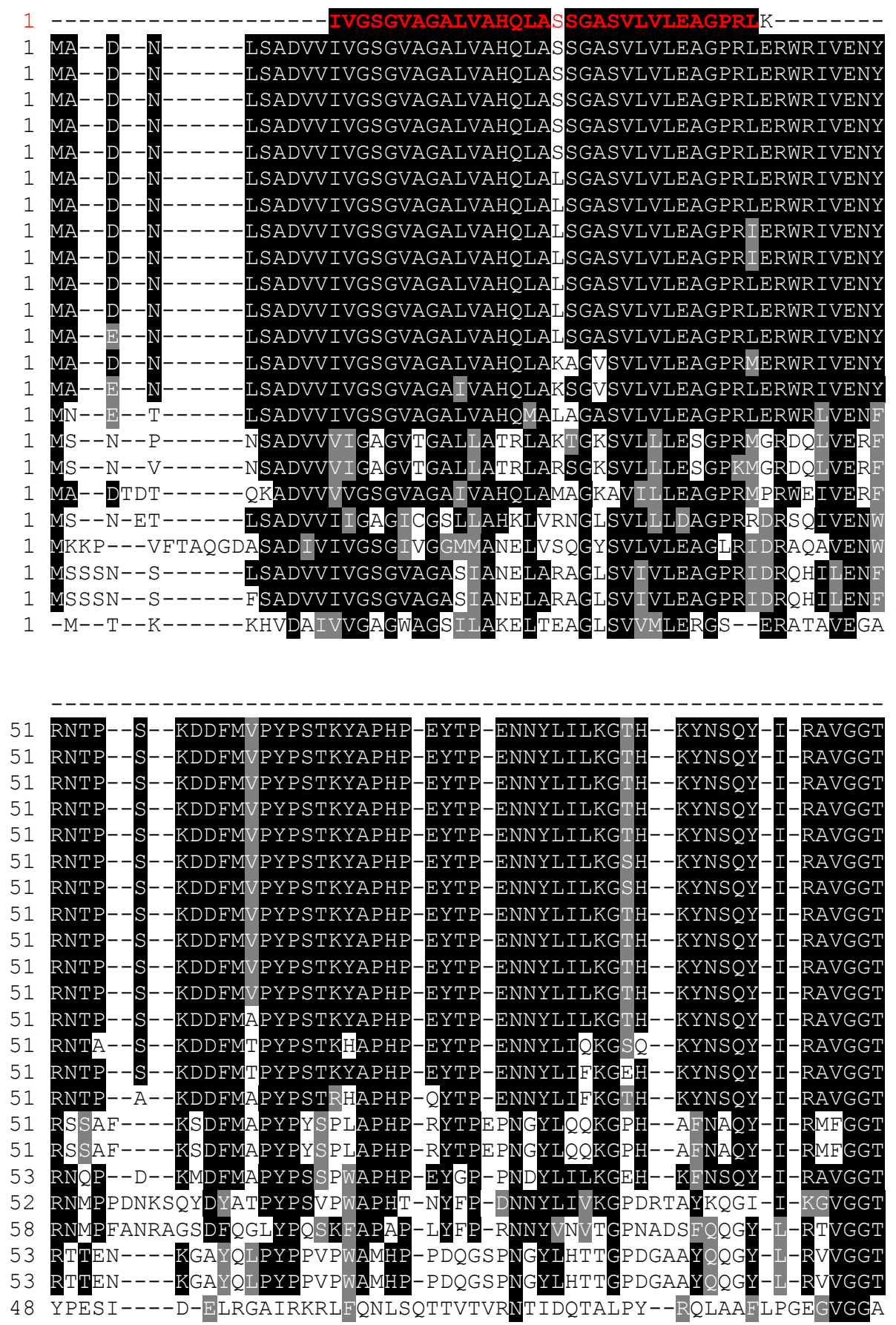
1214 domain

1215 Col_PMB31

1216

1217

1218

1219

1220

1221

1222

1223

1224

1225

1226

1227

1228

1229

1230

1231

1232

1233

1234

1235

1236

1237

1238

1239

1240

1241

1242

1243

1244

1245

1246

1247

1248

1249

1250

1251

1252

1253

1254

1255

1256

1257

1258

1259

1260

1261

1262

1263

1264
Col.prat_Ter291

C.pratensis Ter C.arenae_CaĪ35

Collimonās sp $\mathrm{P}$ C.fungivorans T C. fungivorans $\mathrm{T}$ C.arenae Ter $2 \overline{8} 2$ C.arenae Ter10

Collimonās_sp_o Collimonas_sp O Collimonas_sp_o Glaciimonas_sp_ Glaciimonas sp Janthin_UBA $\overline{1} 13 \overline{4}$ Herba_seropedic Herba_rubrisuba AAN39 $\overline{6} 86.1$ Burkh BAM93252.1Gluco AAF21261.1Panto AFW02570.1Gluco BAD60913.1

Glucon_frateuri

domain

Col PMB31

Col.prat_Ter291 C.pratensis Ter C.arenae_Caİ35 Collimonas_sp_P C.fungivorans $T$ C.fungivorans $\mathrm{T}$ C.arenae Ter $2 \overline{8} 2$ C.arenae_Ter10

Collimonas_sp_o Collimonas_sp_o Collimonas sp 0 Glaciimonas_s $\bar{s}$ Glaciimonas sp Janthin_UBA $\overline{1} 13 \overline{4}$ Herba_seropedic Herba rubrisuba AAN39686.1Burkh BAM93252.1Gluco AAF21261.1Panto AFW02570.1Gluco BAD 60913.1

Glucon_frateuri
101

101

101

101

101

101

101

101

101

101

101

101

101

101

101

102

102

103

108

114

106

106 101

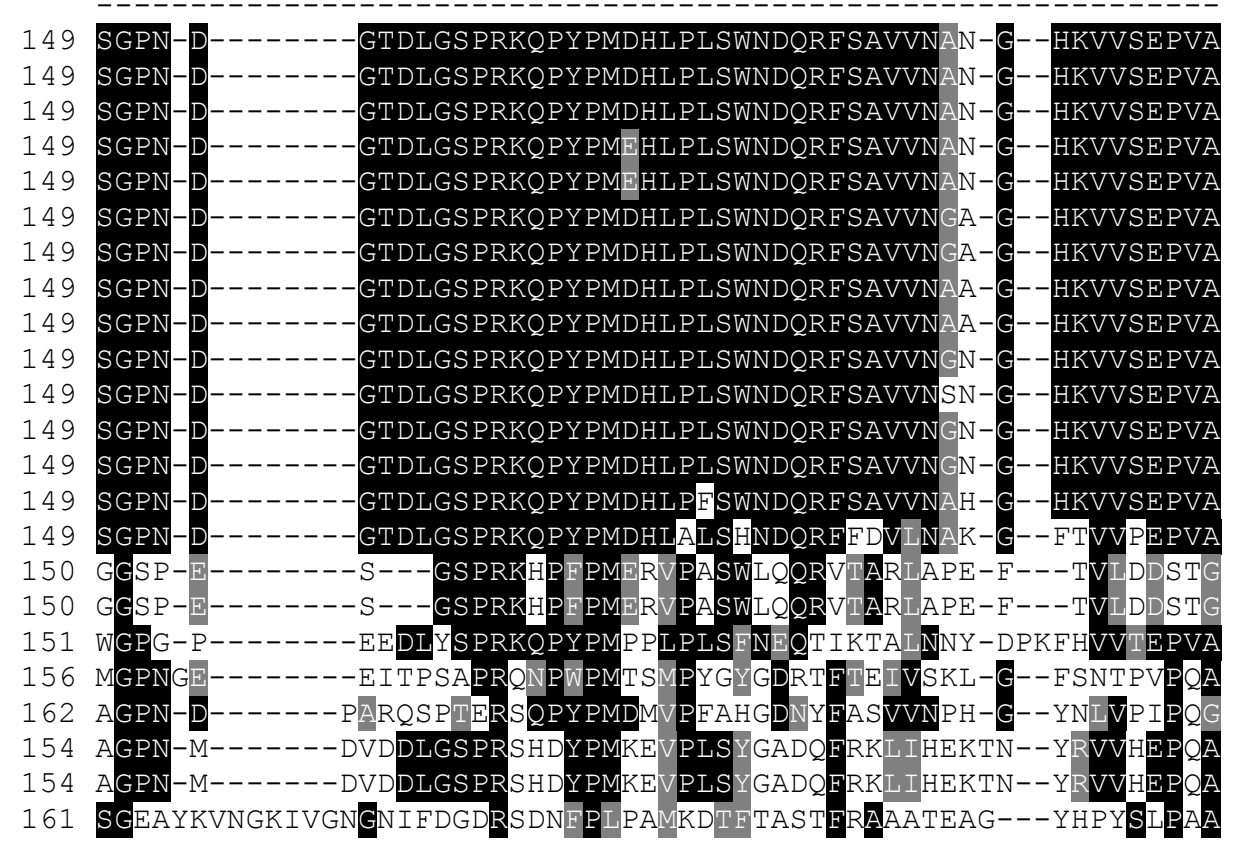


1265

1266

1267

1268

1269

1270

1271

1272

1273

1274

1275

1276

1277

1278

1279

1280

1281

1282

1283

1284

1285

1286

1287

1288

1289

1290

1291

1292

1293

1294

1295

1296

1297

1298

1299

1300

1301

1302

1303

1304

1305

1306

1307

1308

1309

1310

1311

1312

1313

1314

1315
Domain 2 GMC N Col_PMB31

Col.prat_Ter291 C.pratensis Ter C.arenae_Caİ35

Collimonās sp $\mathrm{P}$ C.fungivorans T C.fungivorans ${ }^{T}$ C.arenae Ter $2 \overline{8} 2$ C.arenae Ter10

Collimonās_sp_o Collimonas sp O Collimonas sp 0 Glaciimonas sp Glaciimonas sp Janthin UBA $\overline{1} 13 \overline{4}$ Herba_seropedic Herba_rubrisuba AAN39 $\overline{6} 86.1$ Burkh BAM93252.1Gluco AAF21261.1Panto AFW02570.1Gluco BAD 60913.1

Glucon_frateuri

Domain 2 GMC_N Col PMB31

Col.prat_Ter291 C.pratensis Ter C.arenae Caİ35 Collimonás_sp P C.fungivorans $T$ C.fungivorans ${ }^{-} \mathrm{T}$ C.arenae Ter $2 \overline{8} 2$ C.arenae Ter10 Collimonās sp o Collimonas_sp_o Collimonas sp 0 Glaciimonass_sp Glaciimonas sp Janthin_UBA $\overline{1} 13 \overline{4}$ Herba seropedic Herba rubrisuba AAN39686.1Burkh BAM93252.1Gluco AAF21261.1Panto AFW02570.1Gluco BAD 60913.1

Glucon frateuri
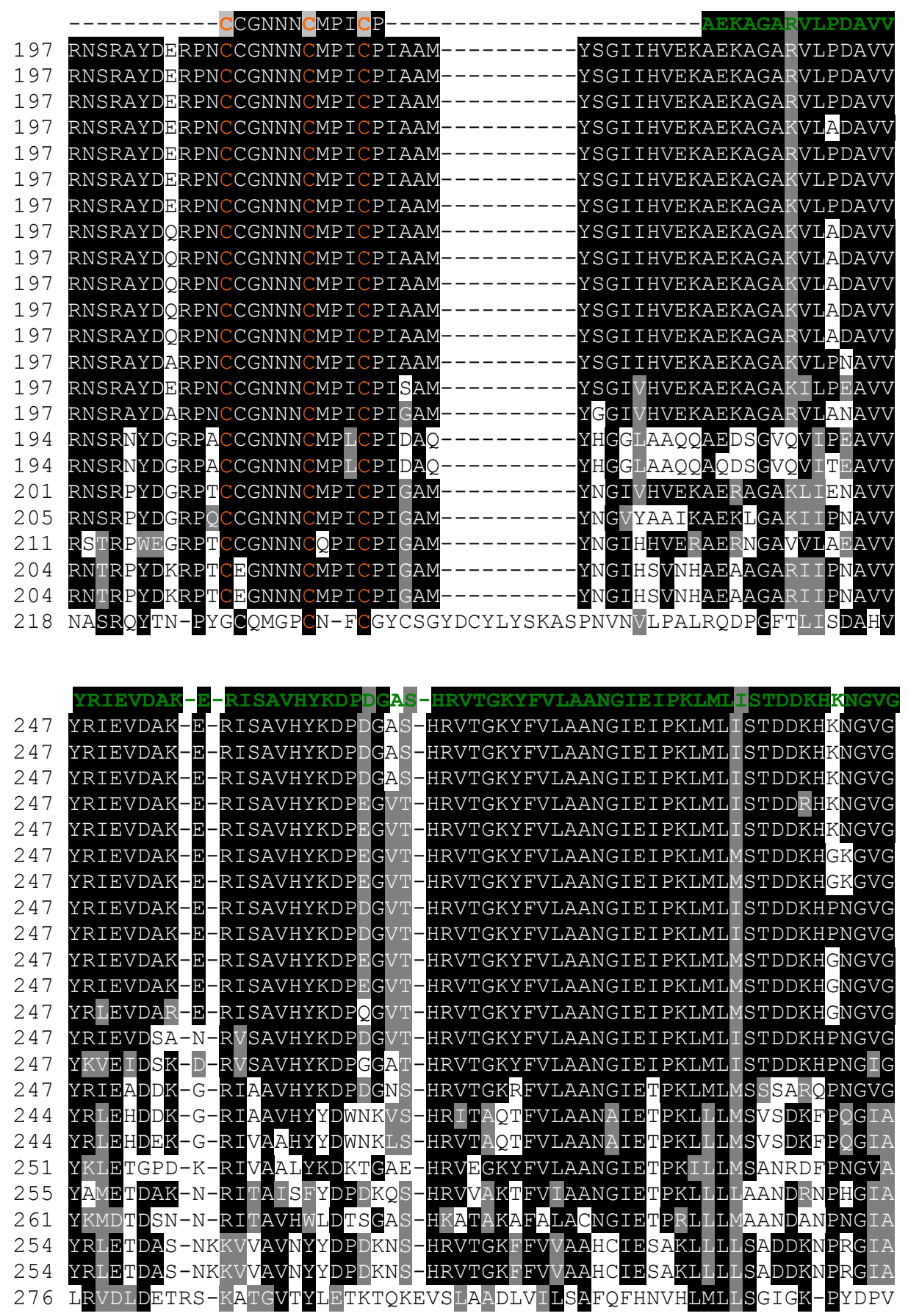
1316 Domain 2 GMC N

1317

1318

1319

1320

1321

1322

1323

1324

1325

1326

1327

1328

1329

1330

1331

1332

1333

1334

1335

1336

1337

1338

1339

1340

1341

1342

1343

1344

1345

1346

1347

1348

1349

1350

1351

1352

1353

1354

1355

1356

1357

1358

1359

1360

1361

1362

1363

1364

1365

1366 Domain 2 GMC_N
Col_PMB31

Col.prat_Ter291 C.pratensis Ter C.arenae_CaĪ35

Collimonās sp $\mathrm{P}$ C.fungivorans T C.fungivorans ${ }^{-} \mathrm{T}$ C.arenae Ter $2 \overline{8} 2$ C.arenae Ter10

Collimonás_sp_o Collimonas sp_o Collimonas_sp_o Glaciimonas_sp_ Glaciimonas_spJanthin_UBA $\overline{1} 13 \overline{4}$ Herba_seropedic Herba_rubrisuba AAN39686.1Burkh BAM93252.1Gluco AAF21261.1Panto AFW02570.1Gluco BAD 60913.1

Glucon_frateuri

Domain 3 GMC_C Col PMB31

Col.prat_Ter291 C.pratensis Ter C.arenae_Cāj35 Collimonás_sp_P C.fungivorans_T C.fungivorans $\mathrm{T}$ C.arenae Ter $2 \overline{8} 2$ C.arenae_Ter10 Collimonas_sp_o Collimonas_sp_o Collimonas sp 0 Glaciimonass_s $\bar{p}$ Glaciimonas sp Janthin_UBA $\overline{1} 13 \overline{4}$ Herba_seropedic Herba-rubrisuba AAN39686.1Burkh BAM93252.1Gluco AAF21261.1Panto AFW02570.1Gluco BAD 60913.1

Glucon frateuri
304

304

304

304

304

304

304

304

304

304

304

304

304

304

304

301

301

308

312

318

312

312

334
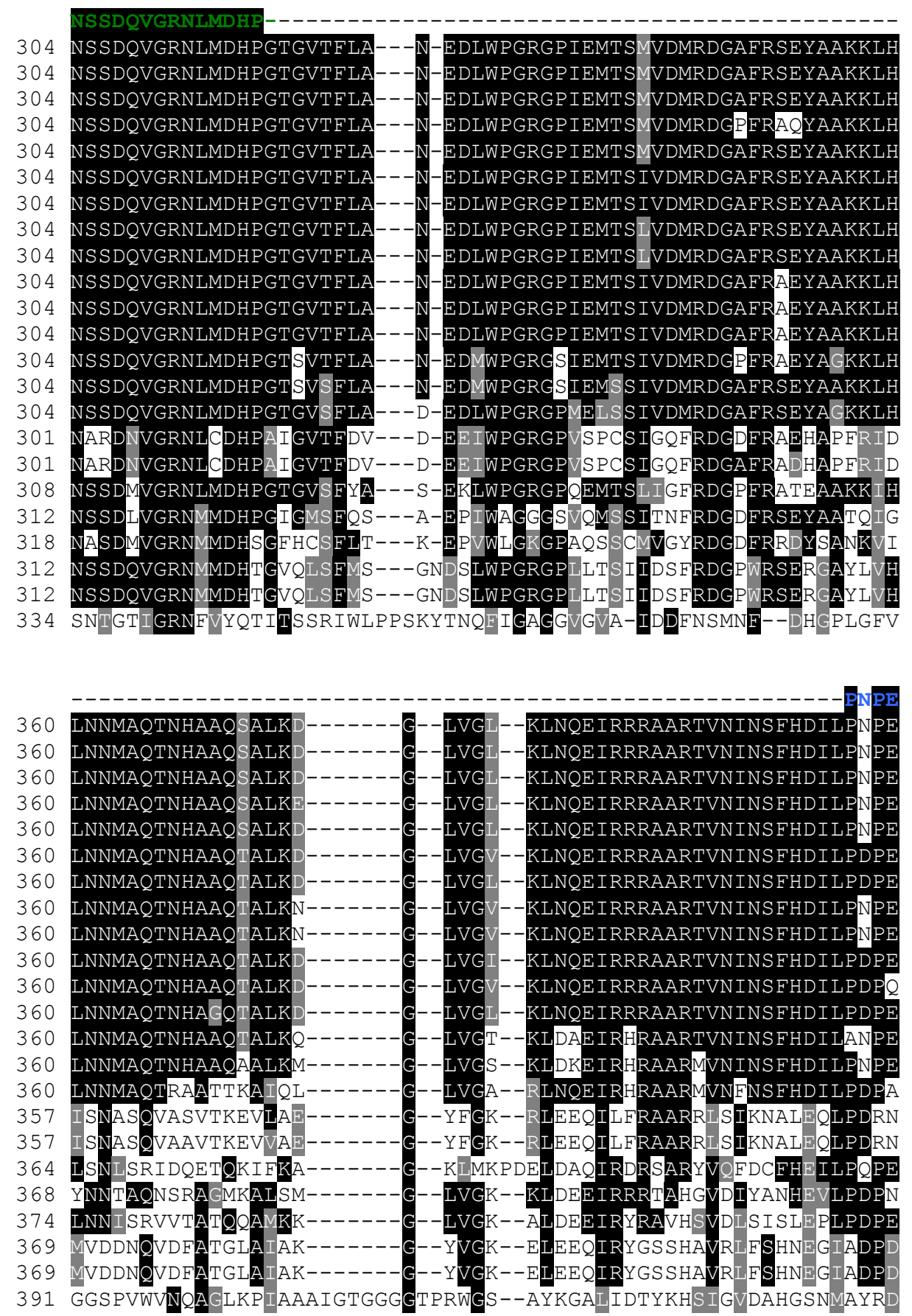

.


Picard et al.

1367 Domain 3 GMC C

1368

1369

1370

1371

1372

1373

1374

1375

1376

1377

1378

1379

1380

1381

1382

1383

1384

1385

1386

1387

1388

1389

1390

1391

1392

1393

1394

1395

1396

1397

1398

1399

1400

1401

1402

1403

1404

1405

1406

1407

1408

1409

1410

1411

1412

1413

1414

1415

1416

1417

Col PMB31 -

Col.prat_Ter291

C.pratensis Ter C.arenae_CaĪ35

Collimonās sp $\mathrm{P}$ C.fungivorans $T$ C.fungivorans ${ }^{-}$ C.arenae Ter $2 \overline{8} 2$ C.arenae Ter10

Collimonās_sp_o Collimonas sp o Collimonas_sp_o Glaciimonas_sp_ Glaciimonas sp Janthin_UBA $\overline{1} 13 \overline{4}$ Herba_seropedic Herba_rubrisuba AAN39 $\overline{6} 86.1$ Burkh BAM93252.1Gluco AAF21261.1Panto AFW02570.1Gluco BAD 60913.1

Glucon_frateuri

Domain 3 GMC_C Col PMB31

Col.prat_Ter291 C.pratensis Ter C.arenae_Caİ35 Collimonás_sp_P C.fungivorans $T$ C.fungivorans $\mathrm{T}$ C.arenae Ter $2 \overline{8} 2$ C.arenae_Ter10

Collimonas_sp_o Collimonas_sp_o Collimonas sp 0 Glaciimonass_sp Glaciimonas sp Janthin_UBA $\overline{1} 13 \overline{4}$ Herba seropedic Herba rubrisuba AAN396̄86.1Burkh BAM93252.1Gluco AAF21261.1Panto AFW02570.1Gluco BAD 60913.1

Glucon_frateuri
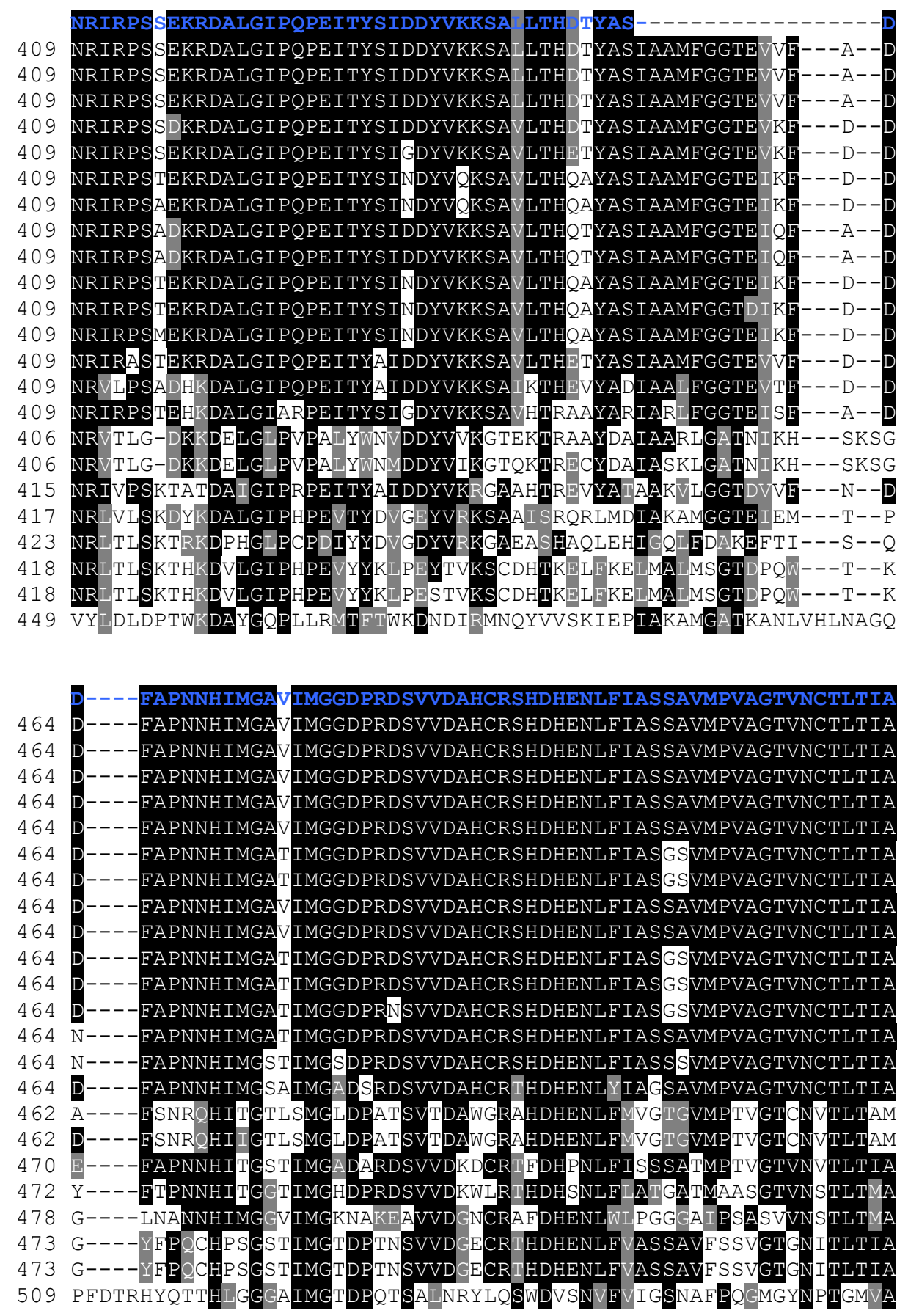


\begin{tabular}{|c|c|c|c|}
\hline 418 & Domain 3 GMC_C & & \\
\hline 1419 & Col_PMB31 & 520 & \\
\hline 1420 & Col-prat_Ter291 & 520 & \\
\hline 421 & C.pratensis_Ter & 520 & \\
\hline 42 & C.arenae_Cā̇35 & 520 & \\
\hline 12 & Collimonās_sp_P & 520 & \\
\hline 12 & C.fungivorans T & 520 & \\
\hline 25 & C.fungivorans ${ }^{-} \mathrm{T}$ & 520 & \\
\hline 426 & C.arenae_Ter $2 \overline{8} 2$ & 520 & \\
\hline 12 & C.arenae_Ter10 & 520 & \\
\hline 12 & Collimonās_sp_o & 520 & \\
\hline 29 & Collimonas_sp_o & 520 & \\
\hline 30 & Collimonas_sp_o & 520 & \\
\hline 431 & Glaciimonas_s $\bar{p}_{-}$ & 520 & \\
\hline 432 & Glaciimonas_sp_ & 520 & \\
\hline 433 & Janthin_UBA $\overline{1} 13 \overline{4}$ & 520 & \\
\hline 1434 & Herba_sēropedic & 518 & $-----\mathrm{RH}$ \\
\hline 1435 & Herba_rubrisuba & 518 & $-----\mathrm{RH}-$ \\
\hline 1436 & AAN39 $\overline{6} 86.1$ Burkh & 526 & -------- \\
\hline 1437 & BAM93252.1Gluco & 528 & $-------\mathrm{KQ}-\mathrm{G}$ \\
\hline 1438 & AAF21261.1Panto & 534 & $-------K G D A$ \\
\hline 143 & AFW02570.1Gluco & 529 & $------\mathrm{LH}-\mathrm{A}$ \\
\hline 1440 & BAD 60913.1 & 529 & $-------\mathrm{LH}-\mathrm{A}$ \\
\hline 441 & Glucon_frateuri & 569 & LKS PGPLVQ-A \\
\hline
\end{tabular}

1442

1443

1444 Figure S2: Highlight of the active domains detected in the large subunit of the GMC 1445 enzyme and of the cysteine rich region

1446 Domain 1 : FAD ; Domain 2 and 3 correspond to GMC sites. Each line corresponds to a 1447 protein sequence and its localisation. The abbreviations correspond to those presented in the 1448 phylogenetic tree in Figure 6. Gluc_BAH805545.1, gluconate dehydrogenase; 1449 Gluc_BAD60913.1, sorbitol dehydrogenases; Burkholderia, glucose dehydrogenase; 1450 Gluc_japonicus, fructose dehydrogenase; Pantoea_agglo., choline dehydrogenase; 


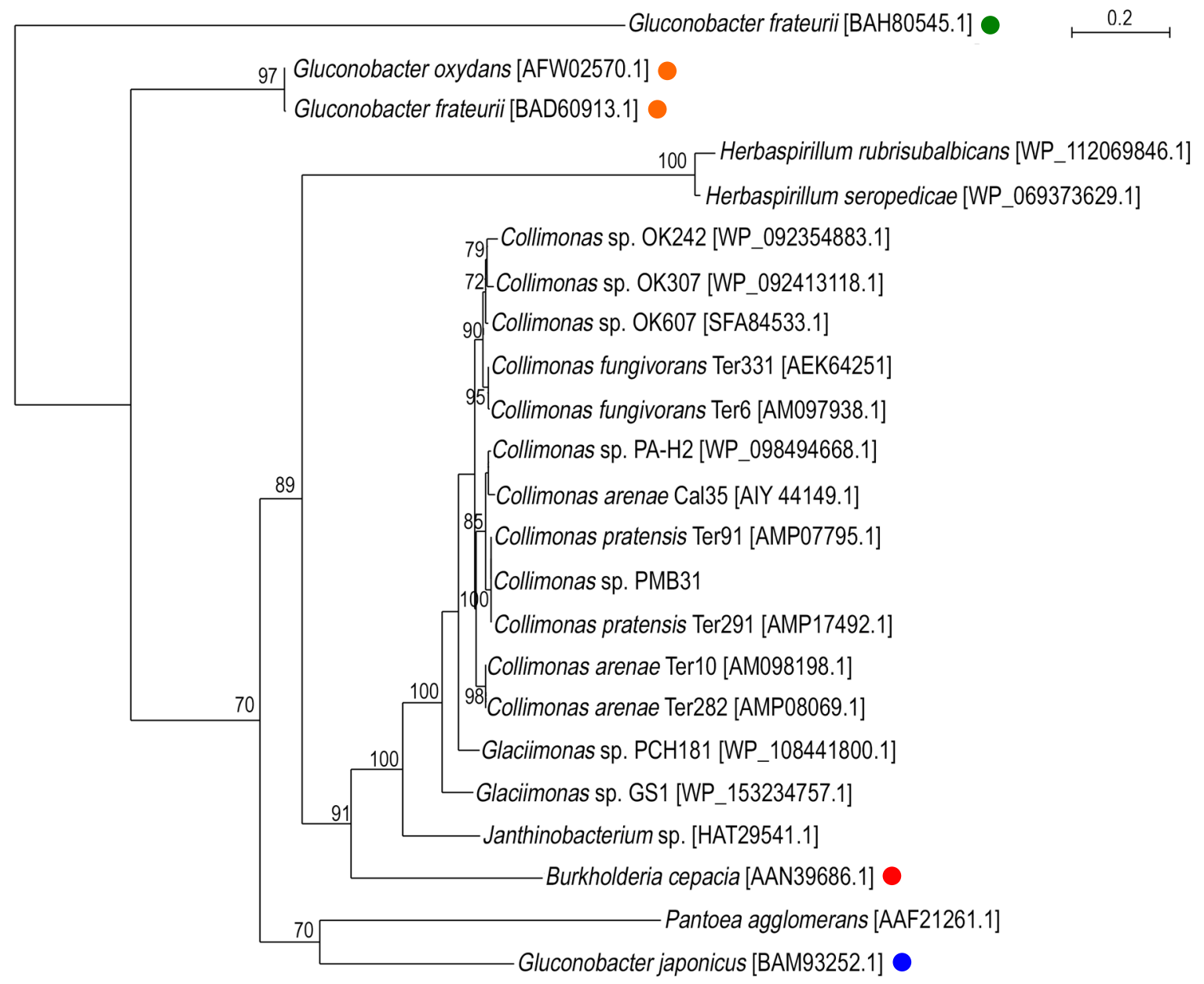

1454 Figure S3: Phylogenetic tree based on protein sequence of the large subunit of different GMC-DH Comparison of the GdhL sequence from PMB3(1) with homologous protein sequences from a set of 22 different genera or species related to Collimonas and available on international databases were analysed among them, 11 were assigned to the Collimonas genus. Other 1459 genera taxonomically close to Collimonas were chosen (Glaciimonas, Janthinobacterium, Herbaspirillum and Burkholderia). Enzymes belonging to the GMC family and with a 1461 demonstrated function were included in the analysis such as Gluconate DH (GADH ; green 1462 circle), Sorbitol DH (SDH ; orange circle), Frcutose DH (FDH ; blue circle) and Glucose DH 1463 (GDH ; red circle). For these protein sequences, the accession number from NCBI is indicated 1464 between brackets. 
Picard et al.

1465

1466

1467

1468

1469

1470 